\title{
Evolution of insect olfactory receptors
}

\section{Christine Missbach ${ }^{1 *}$, Hany KM Dweck ${ }^{1}$, Heiko Vogel ${ }^{2}$, Andreas Vilcinskas ${ }^{3}$, Marcus C Stensmyr ${ }^{4}$, Bill S Hansson ${ }^{1 \dagger}$, Ewald Grosse-Wilde ${ }^{1{ }^{\dagger}}$}

${ }^{1}$ Department of Evolutionary Neuroethology, Max Planck Institute for Chemical Ecology, Jena, Germany; ${ }^{2}$ Department of Entomology, Max Planck Institute for Chemical Ecology, Jena, Germany; ${ }^{3}$ Institute of Phytopathology and Applied Zoology, Justus-Liebig-Universität Gießen, Gießen, Germany; ${ }^{4}$ Department of Biology, Lund University, Lund, Sweden
*For correspondence: cmissbach@ice.mpg.de (CM); Grosse-Wilde@ice.mpg.de (EG-W)

tThese authors contributed equally to this work as senior authors.

Competing interests: The authors declare that no competing interests exist.

Funding: See page 19

Received: 18 December 2013 Accepted: 17 February 2014 Published: 26 March 2014

Reviewing editor: Gáspár Jékély, Max Planck Institute for Developmental Biology, Germany

(c) Copyright Missbach et al. This article is distributed under the terms of the Creative Commons Attribution License, which permits unrestricted use and redistribution provided that the original author and source are credited.
Abstract The olfactory sense detects a plethora of behaviorally relevant odor molecules; gene families involved in olfaction exhibit high diversity in different animal phyla. Insects detect volatile molecules using olfactory (OR) or ionotropic receptors (IR) and in some cases gustatory receptors (GRs). While IRs are expressed in olfactory organs across Protostomia, ORs have been hypothesized to be an adaptation to a terrestrial insect lifestyle. We investigated the olfactory system of the primary wingless bristletail Lepismachilis y-signata (Archaeognatha), the firebrat Thermobia domestica (Zygentoma) and the neopteran leaf insect Phyllium siccifolium (Phasmatodea). ORs and the olfactory coreceptor (Orco) are with very high probability lacking in Lepismachilis; in Thermobia we have identified three Orco candidates, and in Phyllium a fully developed OR/Orco-based system. We suggest that ORs did not arise as an adaptation to a terrestrial lifestyle, but evolved later in insect evolution, with Orco being present before the appearance of ORs.

DOI: 10.7554/eLife.02115.001

\section{Introduction}

All living organisms, including bacteria, protozoans, fungi, plants, and animals, detect chemicals in their environment. The sensitivity and chemical range of animal olfactory systems is remarkable, enabling animals to detect and discriminate between thousands of different odor molecules. Although there is a striking evolutionary convergence towards a conserved organization of signaling pathways in vertebrate and invertebrate olfactory systems (Hildebrand and Shepherd, 1997), the involved receptor gene families evolved independently. The molecular identity of olfactory receptors was first unraveled in vertebrates (Buck and Axel, 1991). In mammals, as many as 1000 heterotrimeric GTP-binding protein (or G protein)-coupled receptors are considered to be employed in olfactory discrimination (Buck and Axel, 1991). A similar number of chemoreceptors, with about 1300 receptor genes and 400 pseudogenes, have been hypothesized for Caenorhabditis elegans (Robertson and Thomas, 2006).

All data on insect olfactory receptors are based on studies investigating the neopteran insects (overview of insect order relationship is given in Figure 1). The identity of receptors involved in olfaction in the evolutionarily more ancient apterygote insects (Archaeognatha, Zygentoma) and paleopteran insects (Odonata and Ephemeroptera) is thus completely unknown. In neopteran insects (Polyneoptera, Paraneoptera, and Holometabola) most volatile stimuli are recognized by members of the olfactory receptor family (ORs). ORs are multitransmembrane domain proteins unrelated to nematode or vertebrate olfactory receptors (Mombaerts, 1999; Robertson, 2001; Hill et al., 2002), displaying a distinct membrane topology (Benton et al., 2006; Lundin et al., 2007). The number of functional OR genes varies from 10 in the human body louse Pediculus humanus humanus (Kirkness et al., 2010) to about 60 in Drosophila melanogaster (Clyne et alı, 1999; Gao and Chess, 1999; Vosshall et al., 1999) and up to 350 OR genes in ants (Zhou et al., 2012). ORs have been suggested 
eLife digest Detecting chemical cues can be a matter of life or death for insects, and many employ three families of receptor proteins to detect a broad range of odors. Members of one of these receptor families, the olfactory receptors, form a complex with another protein, the olfactory coreceptor that is essential for both positioning and stabilizing the receptor, as well as the actual function.

Crustaceans share a common ancestor with insects, and since they do not have olfactory receptors it has been proposed that these receptors evolved when prehistoric insects moved from the sea to live on land. According to this idea, olfactory receptors evolved because these ancestors needed to be able to detect odor molecules floating in the air rather than dissolved in water.

Previous research on insect olfactory receptors has focused on insects with wings. Missbach et al. have now used a wide range of techniques to investigate how evolutionarily older wingless insect groups detect scents. As all investigated groups evolved from a common ancestor at different times these experiments allow tracking of the historical development of olfactory receptors.

In the wingless species that is more closely related to the flying insects there was evidence of the presence of multiple coreceptors but not the olfactory receptors themselves. In the most basal insects no evidence for any part of the olfactory receptor-based system was found. This indicates that the main olfactory receptors evolved independently of the coreceptor long after the migration of insects from water to land. Missbach et al. suggest that olfactory receptors instead developed far later, around the time when vascular plants spread and insects developed the ability to fly.

DOI: 10.7554/eLife.02115.002

to be distantly related to the gustatory receptors of arthropods, with some proteins containing a signature motif in the carboxyl terminus (Scott et al., 2001).

Insect olfactory receptors function as heteromultimers composed of at least one ligand-specific OR and the coreceptor Orco (Vosshall et al., 1999; Elmore et al., 2003; Krieger et al., 2003; Larsson et al., 2004; Sato et al., 2008; Wicher et al., 2008). Interestingly, while Orco (Vosshall and Hansson, 2011) is highly conserved among insects, the sequences of other olfactory receptor genes exhibit very little sequence similarity even within the same insect order (Krieger et al., 2003), complicating their identification. So far, Orco homologues have been identified in Lepidoptera, Diptera, Coleoptera, Hymenoptera, Hemiptera (Krieger et al., 2003; Pitts et al., 2004; Smadja et al., 2009), and Orthoptera (Yang et al., 2012). Neither Orco nor ORs are present in the genome of the crustacean Daphnia pulex, indicating that ORs are insect specific. However, GRs were found in Crustacea, just as in insects (Peñalva-Arana et al., 2009).

A second receptor family, the variant ionotropic glutamate receptors (IRs), is also involved in insect chemosensation (Benton et al., 2009). IRs act in combinations of up to three subunits; individual odorspecific receptors and one or two of the broadly expressed coreceptors IR25a, IR8a, and IR76b (Abuin et al., 2011). IRs are present in olfactory tissues across the Protostomia (Croset et al., 2010), for example two conserved members of this group were described in the Daphnia genome (Croset et al., 2010) and the coreceptor IR25a homologue is expressed in many, if not all mature OSNs of the American lobster Homarus americanus (Hollins et al., 2003) and the spiny lobster Panulirus argus (Tadesse et alo, 2011). Since crustaceans are the closest relatives of insects (Friedrich and Tautz, 1995; Boore et al., 1998; Regier et al., 2010), IRs are most likely the ancient type of insect olfactory receptor.

But when and why did insect ORs evolve? Hexapods derived from an aquatic crustacean ancestor, probably in the Early Ordovician, approximately 483 mya (Rota-Stabelli et al., 2013). The transition from sea to land meant that molecules needed to be detected in gas phase instead of aquatic solution. Therefore, the olfactory system of a hexapod ancestor had to adapt to the terrestrial conditions and detection of volatile, air-borne chemicals. One proposed hypothesis has been that Orco and ORs of the insect type are an adaptation to this terrestrial lifestyle (Robertson et al., 2003; Krang et al., 2012). To reconstruct an evolutionary scenario for insect ORs, we investigated species belonging to different ancient insect orders, including Archaeognatha (jumping bristletails) and Zygentoma (silverfishes and firebrats), and a neopteran insect belonging to the Phasmatodea (leaf and stick insects) as so far not analyzed control group using morphological, electrophysiological and molecular techniques. 


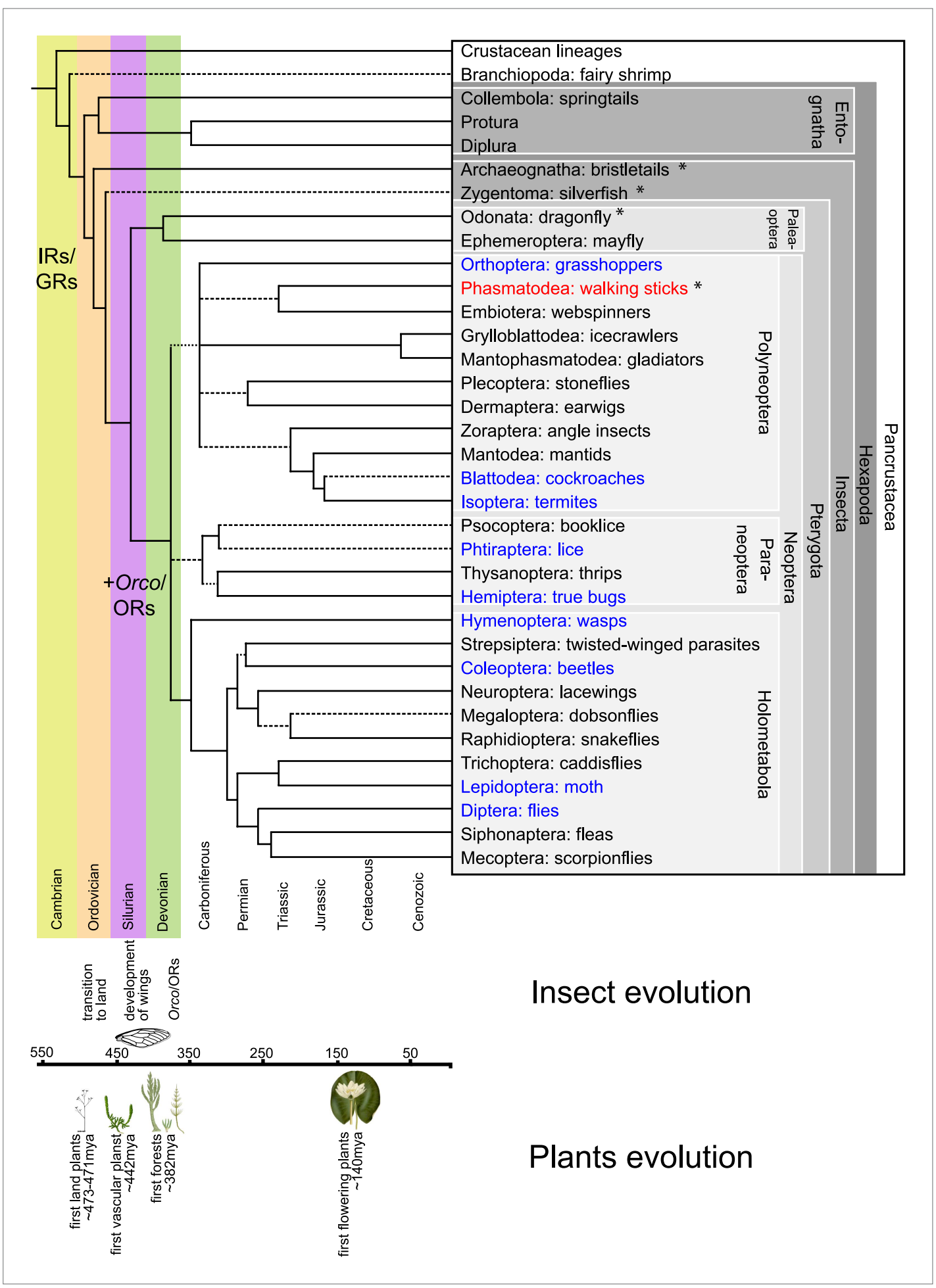

Figure 1. Hexapodan phylogeny. Phylogeny was adapted from Trautwein et al. (2012). Timescale was adjusted for higher level taxa based on Rota-Stabelli et al. (2013), for Holometabola according to Wiegmann et al. (2009) and the remaining groups based on their fossil record (http://insects.about.com/od/evolution/a/Timeline-of-FossilInsects-by-Order.htm), in order to correlate important events in plant and insect evolution with the emergence of insect olfactory receptors. IRs and GRs are known to be much older than insects (Peñalva-Arana et al., 2009; Croset et al., 2010), however, ORs and Orco have evolved during the evolution of insects and cannot be found outside the insect clade (Peñalva-Arana et al., 2009). Insects with a described OR/Orco-based olfactory system Figure 1. Continued on next page 
Figure 1. Continued

were highlighted in blue, whereas species were Orco was described in this study were colored in red. All orders investigated in this study are labeled by an asterisk. Our data suggests the evolution of the coreceptor Orco after the bristletails split from its last common ancestor with the remaining insects. However, an olfactory system that relies both on ORs and Orco seems to have evolved after the emergence of wings. DOI: 10.7554/eLife.02115.003

\section{Results}

Our first step was to analyze the evolutionary ancestry of the insect olfactory system by assessing its complexity in each of three non-holometabolan insects.

To correlate OSN responses with type of sensillum (with pores and grooves) identified in SEM studies of the antennae, we investigated the morphological and physiological characteristics of olfactory sensilla and their olfactory sensory neurons.

\section{Morphology and physiology}

On the antennae of L. y-signata the only putative olfactory sensilla were porous olfactory basiconic sensilla (Figure 2B-E). These sensilla were arranged in a pattern that is highly stereotypical between antennal modules composed of 5-12 annuli, with annuli typically containing zero-to-four Sensilla basiconica (Missbach et al., 2011). Responses to all tested chemical classes of odors, including acids, alcohols, aldehydes, esters, and ketones, were recorded from OSNs housed in these sensilla using the single sensillum recoding measurements (SSR) (Figure 3, uppermost heat map). Based on the response profile, spontaneous activity, and colocalization inside the same sensillum, we identified 12 OSN types, present in five functional basiconic sensillum types. Out of the 12 OSN types, only seven responded to odors tested; two exclusively to acids, while five responded with a similar activity rate to acids or amines and to other odors. OSNs belonging to this second class were broadly tuned and exhibited relatively low spiking activity. In general, OSN classes displayed a low baseline activity with about 1 to 7 spikes/s, with Lys-ab2A that had a spontaneous activity of more than 25 spikes/s as the only exception. Only rarely was an increase in spiking rate of more than 60 spikes per second recorded, even for the best identified ligands (Figure 3source data 1). No responses were obtained for ammonia or pyridine. Coeloconic-like sensilla, s-shaped trichoid sensilla, and chaetic sensilla did not display any morphological features indicating olfactory function and did also not respond to any odor tested (Missbach et al., 2011; data not shown). In conclusion, 7 OSN types that were all housed in basiconic sensilla responded to a wide spectrum of odor molecules.

The morphology of the zygentoman antenna and its sensilla was similar to that of L. $y$-signata, with the presence of grooved sensilla as the only exception (Figure 2G; Adel, 1984; Berg and Schmidt, 1997). Five different functional types of olfactory sensilla were present (Figure 3: three porous, two grooved s. basiconica, the latter are indicated by blue caption). In contrast to L. y-signata, a nascent functional and spatial separation of the detection of amines and acids, and ketones and alcohols appeared in T. domestica. The former primarily elicited responses in OSNs of grooved sensilla, while less polar ones were mainly detected by porous sensilla. However, most of the OSNs in porous sensilla exhibited broad tuning and responded to at least one of the tested acids or amines as well.

We then turned to a neopteran insect. Unlike the other analyzed species, the leaf insect $P$. siccifolium displayed a strong sexual antennal dimorphism, with males having very long antennae covered with trichoid sensilla (Figure 2L), and the females very short antennae without trichoid sensilla (Figure $2 K$ ). In comparison to the wingless insects, the response repertoire of the leaf insect was much more diverse, with a total of 23 different functional sensillum types as identified by SSR recordings (Figure 3). No responses were obtained from trichoid sensilla, but since they were only present on the male antennae they could be involved in detection of an unknown volatile pheromone. In all cases, reported detection of volatile pheromones in insects is dependent on very specific ORs. Taken together these data suggest that leaf insects have a much broader response repertoire with a higher number of different OSN types than the more basal species we analyzed; apparently the number of olfactory receptors has increased. It also seems likely that at least the leaf insect makes use of ORs in odorant detection.

\section{An antennal and maxillary palp transcriptome}

We generated expansive antennal transcriptome datasets of the three insect species, employing a bioinformatics-based approach to identify Orco, ORs, GR, and IRs. In a second transcriptome of 


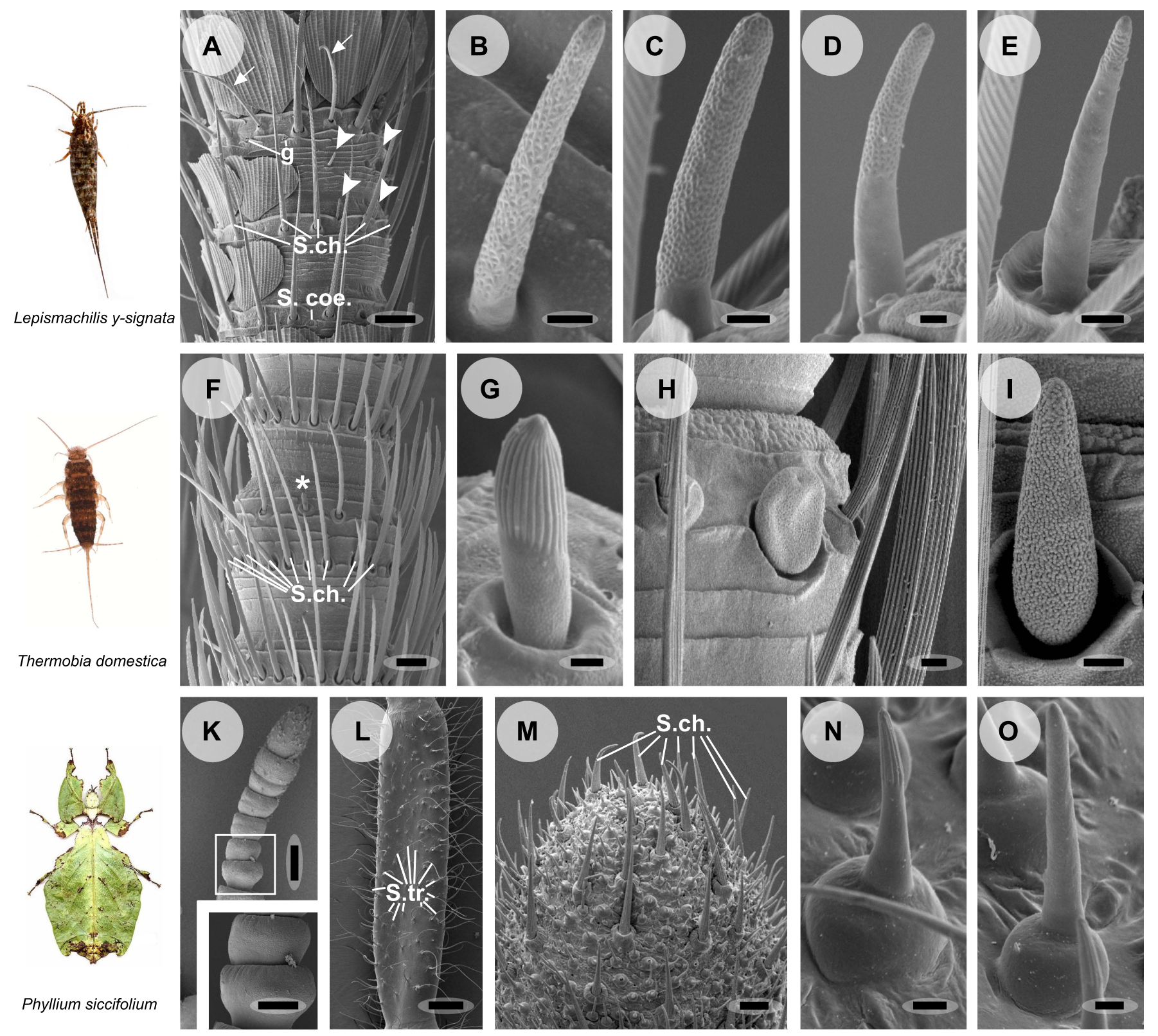

Figure 2. Olfactory sensilla on the antennae of L. $y$-signata (A-E), T. domestica (F-I) and P. siccifolium (K-O). Animals are depicted next to the corresponding antennal SEM images. (A) Detailed view of the antennae of $L$. $y$-signata. The proximal part of the antennae is not only covered with sensilla, but also scales. Glands (g) are highly abundant on the antennae. Many mechanosensory sensilla (S.ch.: Sensilla chaetica) were arranged in circles on the antennal segments. On some antennal segments gustatory sensilla (arrows) can be found between the S.ch (for further information read Missbach et al., 2011). Very rarely zero to four olfactory Sensilla basiconica were identified per segment, in a mostly redundant pattern on the antennae with similar numbers of olfactory sensilla and sensilla types on each antennal segment. Antennal segments are separated by antennal breaking points. The pattern of sensilla is modulated by increasing the number of annuli of a segment through molting. (B-E) Different morphological types of basiconic sensilla. No grooved sensilla/olfactory coeloconic sensilla were identified on the antennae. Only small pegs surrounded by a cuticular wall (s. coe.; referred as coeloconica-like sensillum, Bockhorst 1988) were located on the antennae. These sensilla are not olfactory (for detailed external morphology see Missbach et al., 2011). (F) Detailed view of the antennae of $T$. domestica. The antennal organization is similar to the bristletail, with antennal breaking points and lifelong molting. The most abundant sensilla on the antennae again are mechanosensory S.ch.; beside those gustatory and olfactory sensilla are distributed in a species-specific modular manner over the antennae. (G) In contrast to L. $y$-signata, grooved sensilla can be found on the antennae of T. domestica. ( $\mathbf{H}$ and I) Different morphological types of basiconic sensilla. (K and $\mathbf{L}$ ) Gender specific differences between a female (K) and a male (L) antennae of $P$. siccifolium. Female antennae are short and lack trichoid sensilla (S.tri.). They more or less lack sensilla on the proximal annuli, only the last Figure 2. Continued on next page 
Figure 2. Continued

two annuli are covered with a high number of olfactory and also some mechanosensory sensilla (S.ch.). (M) Male antennal tip. Similar to the distal female antennal annuli the highest density of sensilla can be found on the last annuli. (N and $\mathbf{O}$ ) Both grooved and pored sensilla can be found on these

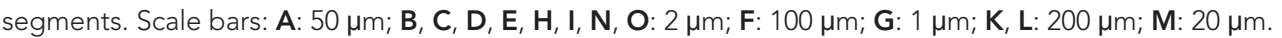

DOI: 10.7554/eLife.02115.004

L. y-signata also maxillary palp RNA was included. In total 99'504'815 reads were generated for the two L. y-signata chemosensory transcriptomes, out of which 77'060'687 were paired end reads. In addition to the transcriptomes of chemosensory tissues, we sequenced pooled RNA of whole bodies and heads resulting in $25^{\prime} 242^{\prime} 666$ reads. This data set was analyzed separately. 27'704'231 and 30'762'777 reads were generated for antennae of $T$. domestica and $P$. siccifolium, respectively (detailed information about transcriptomes and assembly parameters can be obtained from the 'Material and methods' section and Table 1).

\section{No ORs or Orco were found in the transcriptome of $L$. $y$-signata}

The transcriptome data sets were manually screened for genes encoding proteins putatively involved in insect olfaction, including ORs, Orco, GRs, and IRs (number of identified contigs are given in Table 2).

Neither OR-nor Orco-coding transcripts were identified in the transcriptomes of L. $y$-signata using BLAST and HMM domain profile searches as described in the 'Material and methods' section. Custom HMMR-profiles directed against conserved regions of Orco proteins also failed to identify any Orco-related sequences in the bristletail transcriptome. We discovered five GR candidates. MSA analysis of these together with ORs and GRs of various insect species and the Daphnia GRs always confirmed the position of the L. y-signata GR candidates within the GR and not the OR family (Figure 4A, Figure 4-source data 1, Figure 4-source data 2, Figure 4-source data 3, Figure 4-source data 4, Figure 4-source data 5). Since expression levels of gustatory receptors are very low even in gustatory tissue (Clyne et al., 2000; Scott et al., 2001), we argue that ORs or at least Orco should be represented in the large, sensory tissue-specific transcriptome data set of L. $y$-signata if they are indeed part of the olfactory system in the species.

\section{The three Orco-paralogues of T. domestica}

In contrast to L. y-signata, three different Orco-related sequences were identified in the transcriptome of T. domestica. All candidates were cloned as full-length coding sequences using RACE-PCR. The three sequences displayed different similarities to the Orco sequence of $D$. melanogaster, one sequence shared $45.8 \%$, one $35.1 \%$, and the third $24.4 \%$ sequence similarity at the amino acid level. Orco was the protein most similar to all three Orco candidate sequences (Figures 4B and 5), although some of the key amino acids of the coreceptor are substituted at least in TdomOrco3 (Wicher et al., 2008; Sargsyan et al., 2011; Nakagawa et al., 2012; Kumar et al., 2013; highlighted in alignment Figure 5). Apart from the Orco variants, no OR-related sequences were identified, but 9 contigs for GR candidates were found that were assigned to seven GRs, including three candidates close to full length or full length and four additional fragments (Table 2 and Figure 4A).

\section{Normal OR/Orco in the leaf insect}

In the transcriptome data set of $P$. siccifolium, both various OR-related sequences and a single Orco sequence were detected (Table 2). The exact number of OR genes was hard to ascertain since some of the contigs were too short and did not show sufficient sequence overlap in a multiple sequence alignment (MSA) to be confidently identified as independent. However, in total, we identified 30 gene fragments coding ORs, indicating that the transcriptomic approach chosen was applicable to our question, successfully identifying both Orco and ORs in P. siccifolium.

\section{Orco expression in T. domestica}

Considering that for all other insects analyzed so far one Orco is the norm, the appearance of three Orco candidates in T. domestica is highly unusual. We thus assessed the expression of the three candidates in different tissues using RT-PCR. For all three Orco types expression was limited to the antenna (Figure 6). To further assess the expression, we used in situ hybridization employing an antisense probe of one of the coreceptors. This led to staining of single cells below one or two basiconic sensilla of an antennal subsegment (Figure 7), suggesting that TdomOrco1 might indeed be expressed in OSNs. However, only one neuron per sensillum was stained. No signals were obtained when using a sense probe for TdomOrco1 (Figure 7-figure supplement 1). 


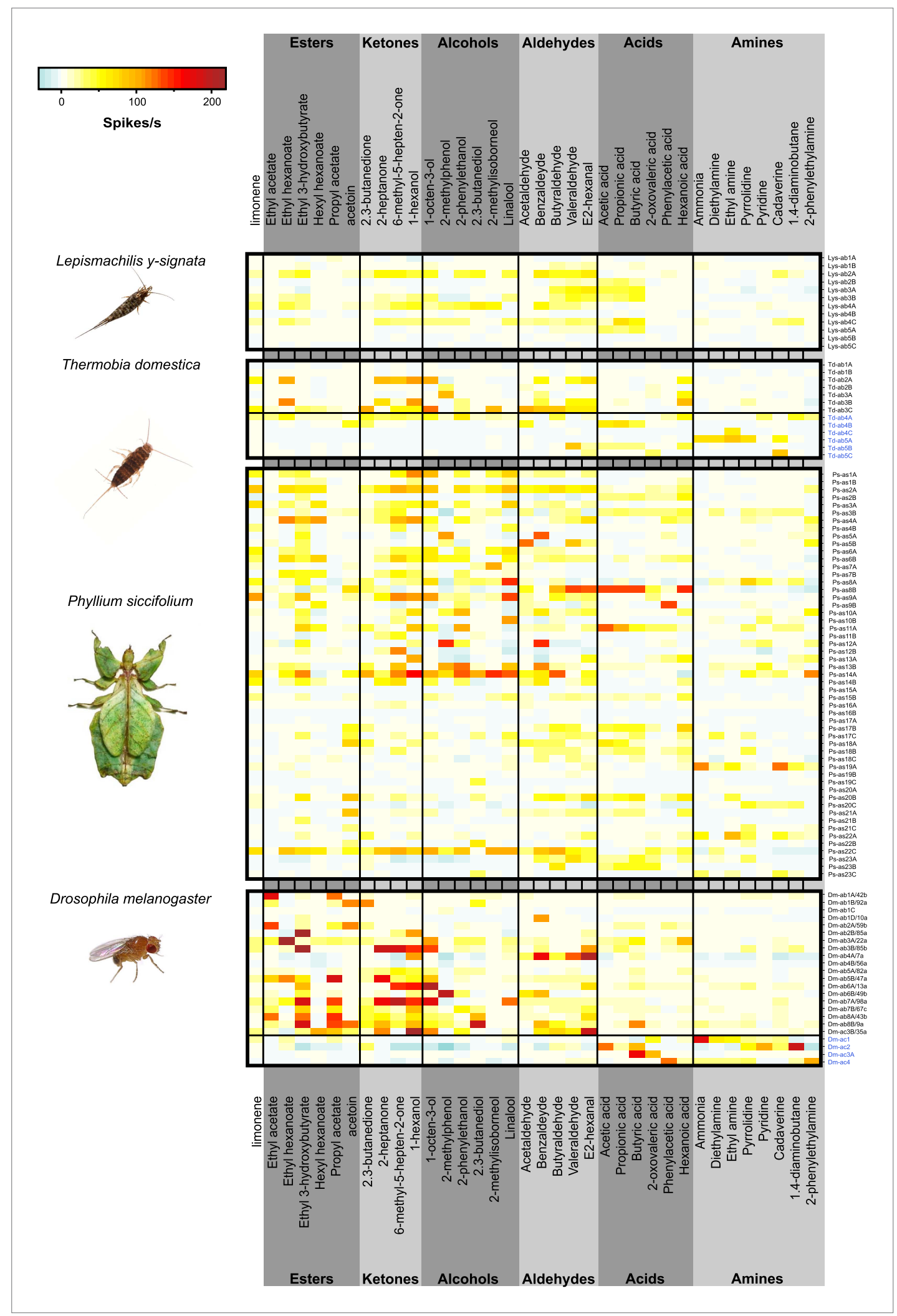

Figure 3. Color coded response profiles of L. y-signata, T. domestica, P. siccifolium and D. melanogaster. Spikes are sorted by neurons, with the exception of ac1, ac2, and ac4 of D. melanogaster where spike sorting was not possible. Means over 5 to 23 recordings were used as basis for visualization (source data are given in Figure 3. Continued on next page 
Figure 3. Continued

Figure 3-source data 1). The same color code was used for all species, ranging from highest to lowest encountered change in activity. Neurons in grooved sensilla are indicated by blue letters (ac). For L. y-signata responses to odors were only obtained from neurons in porous sensilla (ab). A separation between porous and grooved sensilla was not possible for P. siccifolium. Sensilla were classified as antennal sensillum (as). L. y-signata neurons are mostly broadly tuned with comparable low change in spiking activity. For $P$. siccifolium a total of 23 different functional sensillum types were identified in SSR recordings (in comparison five in L. $y$-signata, five in T. domestica) suggesting that leaf insects have a broader response repertoire.

DOI: 10.7554/eLife.02115.005

The following source data are available for figure 3:

Source data 1. Excel file of mean responses and baseline firing rate of the different OSN classes of L.y-signata, T. domestica, P.siccifolium, and D. melanogaster.

DOI: 10.7554/eLife.02115.006

\section{Only IRs in L-y-signata}

As none of the experiments gave a hint for the existence of any OR or Orco-related sequence in the bristletail transcriptome, we focused on the second olfactory receptor family of insects, the IRs. Although we could not identify any OR sequences in the transcriptome, a high number of putative glutamate receptor coding contigs was identified (Table 2). However, only five candidate iGluRs and 14 candidate IRs appeared to be real unigenes, possessing at least two of the three transmembrane domains. Some candidate sequences were extended in $3^{\prime}$-direction using RACE-PCR with antennal cDNA as template, allowing verification of unigene status and antennal expression. In MSA and phylogenetic analysis, the identified IRs grouped with DmellRs (Croset et al., 2010). Among the identified putative LsigIRs were orthologues of the D. melanogaster coreceptors IR25a and IR8a, as well as one receptor similar to IR76b (Figure 8A, Figure 8-source data 1, Figure 8-source data 2, Figure 8-source data 3, Figure 8-source data 4, Figure 8-source data 5). As in other IRs (Benton et al., 2009) one or several key amino acids in the predicted glutamate binding domains were absent in the non-coreceptor IR candidates and LsigIR76b (Figure 8B). 7 out of 14 LsiglRs group close to a cluster of D. pulex IRs and the antennal IRs IR21a and IR68a of D. melanogaster, with no clear relationship to one or the other. None of the Lepismachilis IR candidates grouped with the 'divergent' Drosophila IRs.

We then performed fluorescent in situ hybridization with RNA probes directed against the IR coreceptor candidates (Figure 9). Antisense probes of IR25a and IR8a led to labeling of one to three OSNs underneath basiconic sensilla (Figure 9-figure supplement 1). In control experiments with sense probes, or without any probe, no staining was obtained (Figure 9-figure supplement 2). The pattern of expression of IR coreceptors in OSNs of L. $y$-signata indicates that most OSNs are covered by this gene family.

All experiments thus indicate that the olfactory system of this species employs other receptors like IRs or GRs, with no ORs or Orco present.

\section{Discussion}

Insects provide us with an excellent opportunity to study groups of animals that have retained ancestral characteristics and understand how the specific building blocks in olfaction have evolved in both insects and other animals. Consequently, we selected insects at crucial positions of the phylogenetic tree with a functional olfactory system adapted to terrestrial conditions and detection of volatile chemicals. This species collection provides an excellent model to study the early evolution of the insect olfactory system.

To address which receptors are involved in odor detection in these insects and in basal insects in general, we applied several different approaches. Based on our transcriptome data sets, we suggest a stepwise evolution of the Orco/OR complex with Orco having evolved in the lineage of Dicondylia (Zygentoma + Pterygota) and the functional complex of Orco and ORs emerging within the pterygote insects (this study, Clyne et al., 1999; Gao and Chess, 1999; Smadja et al., 2009; Vosshall et al., 1999; Robertson and Wanner, 2006; Kirkness et al., 2010). Although it is impossible to completely rule out the presence of ORs, none of our extensive experiments led to the identification of either ORs or Orco in the bristletail L. y-signata. The well-established conservation of the Orco 
Table 1. Technical overview of transcriptomes (study accession: PRJEB5093, study unique name: ena-STUDY-MPI

CE-12-12-2013-15:03:23:860-31)

\begin{tabular}{|c|c|c|c|c|c|c|c|c|c|}
\hline Organism & $\begin{array}{l}\text { Sequencing } \\
\text { technique }\end{array}$ & $\begin{array}{l}\text { Number } \\
\text { of reads }\end{array}$ & $\begin{array}{l}\text { Number } \\
\text { of contigs } \\
\text { above } \\
400 \mathrm{bp}\end{array}$ & N50 & $\begin{array}{l}\text { Average } \\
\text { length of } \\
\text { contigs }\end{array}$ & Tissue & $\begin{array}{l}\text { Sample } \\
\text { accession }\end{array}$ & $\begin{array}{l}\text { Secundary } \\
\text { accession }\end{array}$ & $\begin{array}{l}\text { Sample } \\
\text { unique } \\
\text { name }\end{array}$ \\
\hline \multirow[t]{3}{*}{$\begin{array}{l}\text { Lepismachilis } \\
\text { y-signata }\end{array}$} & $\begin{array}{l}\text { HiSeq2000 } \\
\text { (Illumina) }\end{array}$ & $22^{\prime} 444^{\prime} 128$ & $68^{\prime} 984$ & 1'179 & $1^{\prime} 000$ & $\begin{array}{l}\text { antennae } \\
\text { and palps }\end{array}$ & ERS384175 & SAMEA2276780 & Lysig1 \\
\hline & $\begin{array}{l}\text { HiSeq2500 } \\
\text { (Illumina) }\end{array}$ & $\begin{array}{l}77^{\prime} 060^{\prime} 687 \\
\text { paired end }\end{array}$ & & & & antennae & ERS384176 & SAMEA2276781 & Lysig2 \\
\hline & $\begin{array}{l}\text { HiSeq2000 } \\
\text { (Illumina) }\end{array}$ & $25^{\prime} 242^{\prime} 666$ & $37^{\prime} 860$ & & 857 & $\begin{array}{l}\text { heads, whole } \\
\text { bodies }\end{array}$ & ERS399748 & SAMEA2342071 & LysigMix1 \\
\hline $\begin{array}{l}\text { Thermobia } \\
\text { domestica }\end{array}$ & $\begin{array}{l}\text { HiSeq2500 } \\
\text { (Illumina) }\end{array}$ & $\begin{array}{l}27^{\prime} 704^{\prime} 231 \\
\text { paired end }\end{array}$ & 31'172 & 1'349 & $1^{\prime} 070$ & antennae & ERS384177 & SAMEA2276782 & Tdom1 \\
\hline $\begin{array}{l}\text { Phyllium } \\
\text { siccifolium }\end{array}$ & $\begin{array}{l}\text { HiSeq2500 } \\
\text { (Illumina) }\end{array}$ & $\begin{array}{l}30^{\prime} 762^{\prime} 777 \\
\text { paired end }\end{array}$ & $34^{\prime} 653$ & 1'890 & 1'305 & antennae & ERS384178 & SAMEA2276783 & Psic1 \\
\hline
\end{tabular}

Table 2. Number of candidate contigs (not unigenes) for the different gene families identified in the transcriptomes of the different species

\begin{tabular}{lllll} 
Organism & Orco & ORs & GRs & IRs \\
\hline Lepismachilis y-signata & - & - & $7(5$ above $400 \mathrm{bp})$ & $17(16$ above $400 \mathrm{bp})$ \\
\hline Thermobia domestica & $6(1$ above $400 \mathrm{bp})$ & - & $9(3$ above $400 \mathrm{bp})$ & 19 (9 above $400 \mathrm{bp})$ \\
\hline Phyllium siccifolium & 1 (1 above $400 \mathrm{bp})$ & 30 (16 above $400 \mathrm{bp})$ & $6(2$ above $400 \mathrm{bp})$ & $32(19$ above $400 \mathrm{bp})$ \\
\hline
\end{tabular}

DOI: 10.7554/eLife.02115.008

coding gene through evolution suggests that it is highly unlikely that we missed it. We did, however, identify a number of IRs, including the IR coreceptors IR25a, IR8a, and IR76b in the L. y-signata antennal transcriptome. FISH allowed us to visualize expression of the IR co-receptors in a large number of OSNs associated with basiconic sensilla. Based on these results we propose that the olfactory system of L. $y$-signata is not based on ORs.

In insects, different sensillum types house OSNs typically responding to different sets of odors. In D. melanogaster IRs are the functional receptor type of OSNs in double-walled coeloconic sensilla, and ORs are predominantly expressed in OSNs housed in single-walled basiconic and trichoid sensilla (Hallem et al., 2004; Silbering et al., 2011). It follows that this organization cannot exist with just one sensillum type present, as is the case in Archaeognatha (Berg and Schmidt, 1997; Missbach et al., 2011) and older hexapod taxa as the Collembola (Altner and Prillinger, 1980). The oldest insect taxon where double-walled sensilla were investigated is Zygentoma, which have both single-walled basiconic sensilla with pores and double-walled sensilla with spoke channels (Berg and Schmidt, 1997). Coeloconic sensilla differ dramatically from the single-walled trichoid and basiconic types in both wall structure and in internal environment. The coeloconic structure has been thought to be a prerequisite for IR function (Benton et al., 2009; Guo et al., 2014). However, in the Archaeognatha we find that IRs are most likely located in OSNs of Sensilla basiconica. IRs might thus have evolved in a single-walled sensillum and did not find their modern, coeloconic environment until neopteran insects evolved.

In the bristletail L. $y$-signata, we found that many of the OSNs are very broadly tuned, responding to volatiles with several different functional groups at higher doses. However, broadly tuned receptors might not have high affinities. By counting and integrating molecules over longer times, OSNs could include even low-probability binding events in generating their response (Firestein, 2001). This might also mean that the system does not have a high temporal resolution, which seems to be a fair trade-off for a walking insect that lives in its substrate. 


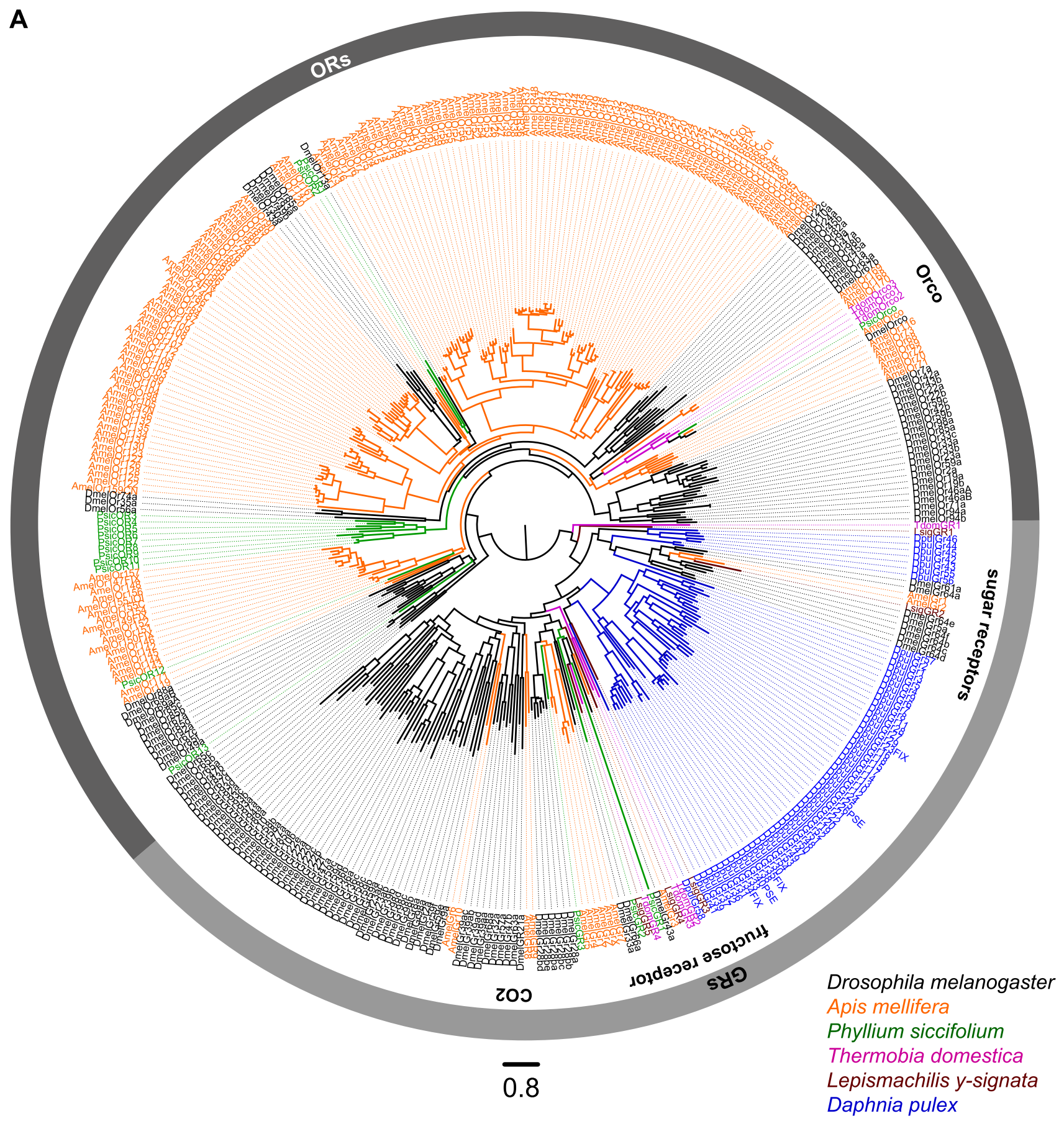

B TdomOrco3

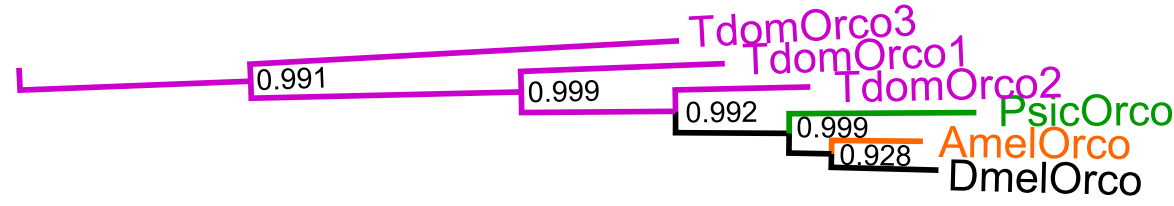

Figure 4. ORs and GRs of L. y-signata, T. domestica, and P. siccifolium. (A) Dendrogram displaying the relationship of identified OR and GR candidates of L. y-signata, T. domestica, and P. siccifolium to D. melanogaster (Clyne et al., 1999; Gao and Chess, 1999; Vosshall et al., 1999) and Apis mellifera (Robertson and Wanner, 2006) GR and OR proteins, and Daphnia pulex GRs (Peñalva-Arana et al., 2009). The dendrogram was determined by Figure 4. Continued on next page 
Figure 4. Continued

maximum likelihood analysis of a MAFFT-Alignment using FastTree2. All L. y- signata candidates group within the GRs. Only candidates with a translated amino acid sequence longer than 120 amino acids and overlap in multiple sequence alignment were taken for analysis, since ORs and GRs are highly divergent and only unigenes should be included in the analysis (all candidate OR and GR sequences of L. y-signata, T. domestica and P. siccifolium are given in Figure 4-source data 1 for amino acids and Figure 4-source data 2 for nucleotide sequences). For T. domestica, we identified three different variant Orco types that were included in the analysis as full length translated amino acid sequences. (B) Blow-up of the dendrogram showing the support values for the coreceptor subgroup. The whole group is well supported.

DOI: 10.7554/eLife.02115.009

The following source data are available for figure 4:

Source data 1. Amino acid sequences of putative olfactory and gustatory receptors of L. y-signata, T. domestica, and P. siccifolium. DOI: 10.7554/eLife.02115.010

Source data 2. Nucleotide sequences of putative olfactory and gustatory receptors of L. y-signata, T. domestica, and P. siccifolium. DOI: 10.7554/eLife.02115.011

Source data 3. MAFFT-alignment of OR and GR candidates of L. y-signata, T. domestica, P. siccifolium and D. melanogaster (Clyne et al., 1999, Gao and Chess, 1999, Vosshall et al., 1999) and Apis mellifera (Robertson and Wanner, 2006) GR and OR proteins, as well as Daphnia pulex GRs done. DOI: 10.7554/eLife.02115.012

Source data 4. FastTree file resulting from the MSA of Figure 4-source data 3 (can be opened with FigTree). DOI: 10.7554/eLife.02115.013

Source data 5. Tree file resulting from the MSA of Figure 4-source data 3 containing node support values (can be opened e.g., with Adobe Illustrator).

DOI: 10.7554/eLife.02115.014

The response spectrum of Drosophila IRs is much narrower than the responses we find in the bristletail. If IRs are the only olfactory receptor type in basal insects they should exhibit a broader spectrum of possible ligands, including acids, aldehydes, alcohols, but also esters and ketones, as revealed in our physiological measurements. One additional observation in the bristletail is that many of those neurons have a broad overlap in their response spectra. One hypothesis to explain an IR-based olfactory system in L. y-signata would be very broad tuning of single receptors, another that the selectivity of OSNs could be regulated by combinations of different IRs.

In D. melanogaster, one conserved IR (IR64a) is expressed in different subpopulations of sensilla in the third chamber of the sacculus (Silbering et al., 2011). Corresponding OSNs are activated either by free protons or organic acids and many other odors, including esters, alcohols, and ketones (Ai et al., 2010). Expression of this IR together with IR8a is both necessary and sufficient for sensitivity towards organic acids and other odors, but probably requires a different, until now unknown cofactor to mediate the specific response of OSNs to inorganic acids and $\mathrm{CO}_{2}$ (Ai et al., 2010).

Alternatively, GR candidates could account for part of the non-neopteran olfactory setup, especially since it has been shown that GRs can add to the olfactory repertoire (Tauxe et al., 2013). Putative contact chemosensory sensilla are highly abundant on the antennae of L. $y$-signata (Missbach et al., 2011) and T. domestica (Adel, 1984). Both detection of sugars/amino acids (shown for T. domestica: Hansen-Delkeskamp, 2001) and a proposed contact-pheromone (Fröhlich and Lu, 2013) likely involve GRs, indicating that involvement of the limited set of GRs beyond this scope is unlikely.

However, these data do not explain the presence of three different Orco variants in the firebrat. So far only one Orco orthologue has been identified in each studied insect species (e.g., Krieger et al., 2003; Pitts et al., 2004; Smadja et al., 2009; Yang et al., 2012). All T. domestica variants were found to be expressed in antennae, suggesting their involvement in chemosensation. TdomOrco 3 even has an amino acid exchange of a functional important residue from asparagine to glutamic acid at position 466. This residue was demonstrated as critical for the ion channel function in D. melanogaster, where substitution of D466 with amino acids other than glutamic acid resulted in a substantial reduction in channel activity, but substitution to glutamic acid leads to an increase in sensitivity of the heteromeric receptor complex (Kumar et al., 2013). Additionally, this residue is highly conserved across insects (Kumar et al., 2013) including two of the three T. domestica Orcos (this study).

While the antennal expression argues for a potential involvement in chemosensation, the existence of three Orco types remains mysterious. It will be part of future studies to investigate if the Orco candidates form heterodimers with other receptors like GRs or with each other to build functional receptors or if they fulfill a channel function in other processes than olfaction. 


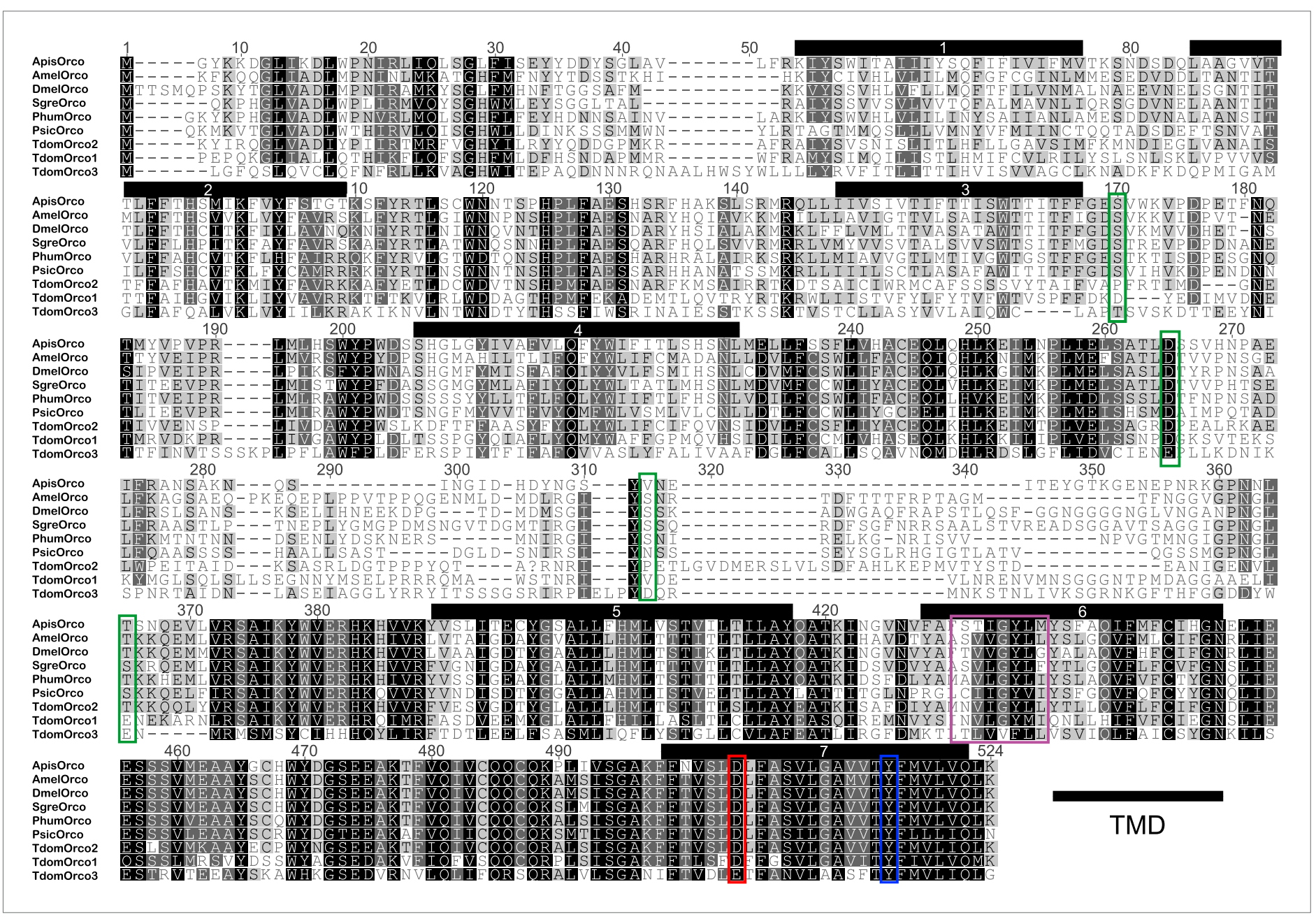

Figure 5. Multiple sequence alignment of T. domestica Orcos. Alignment of T. domestica Orcos with Orcos of Acyrthosiphon pisum (GI:328723530), A. mellifera (GI:201023349), D. melanogaster (GI:24644231), Schistocerca gregaria (GI:371444780), Pediculus humanus corporis (GI:242009783), P. siccifolium (this study). Important amino acids are highlighted in colored boxes (purple: effect on ion permeability, Wicher et al., 2008; green: phosophorylation sites for PKC of DmelOrco, Sargsyan et al., 2010; blue: affect spontaneous and evoked action potentials in receptor complex, Nakagawa et al., 2012; red: important residue for channel activity, Kumar et al., 2013).

DOI: 10.7554/eLife.02115.015

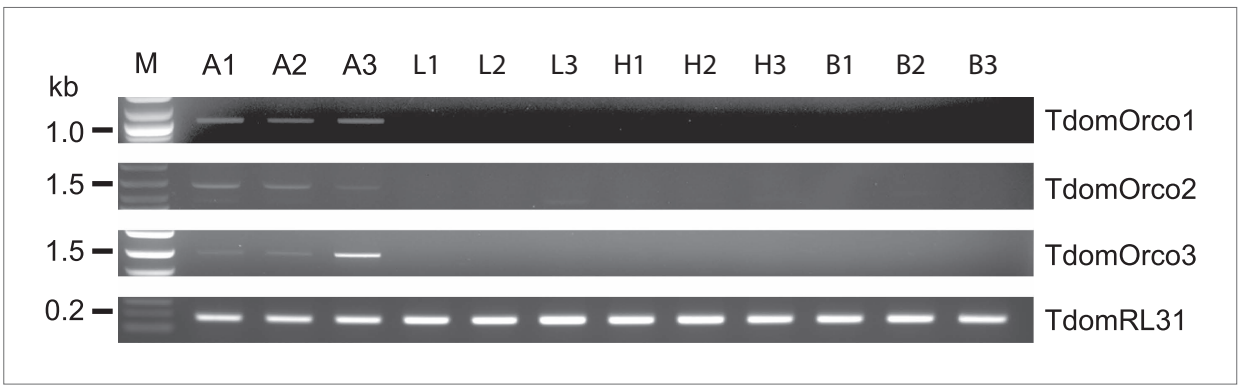

Figure 6. Expression of $T$. domestica Orcos. Using RT-PCR Orco expression was detected in the antennae (A) of $T$. domestica, but not in legs $(\mathrm{L})$, heads without antennae and palps $(H)$, and bodies $(B)$. Primer sequences are given in Figure 6-source data 1.

DOI: 10.7554/eLife.02115.016

The following source data are available for figure 6:

Source data 1. Primers and their properties used in this study. DOI: 10.7554/eLife.02115.017 


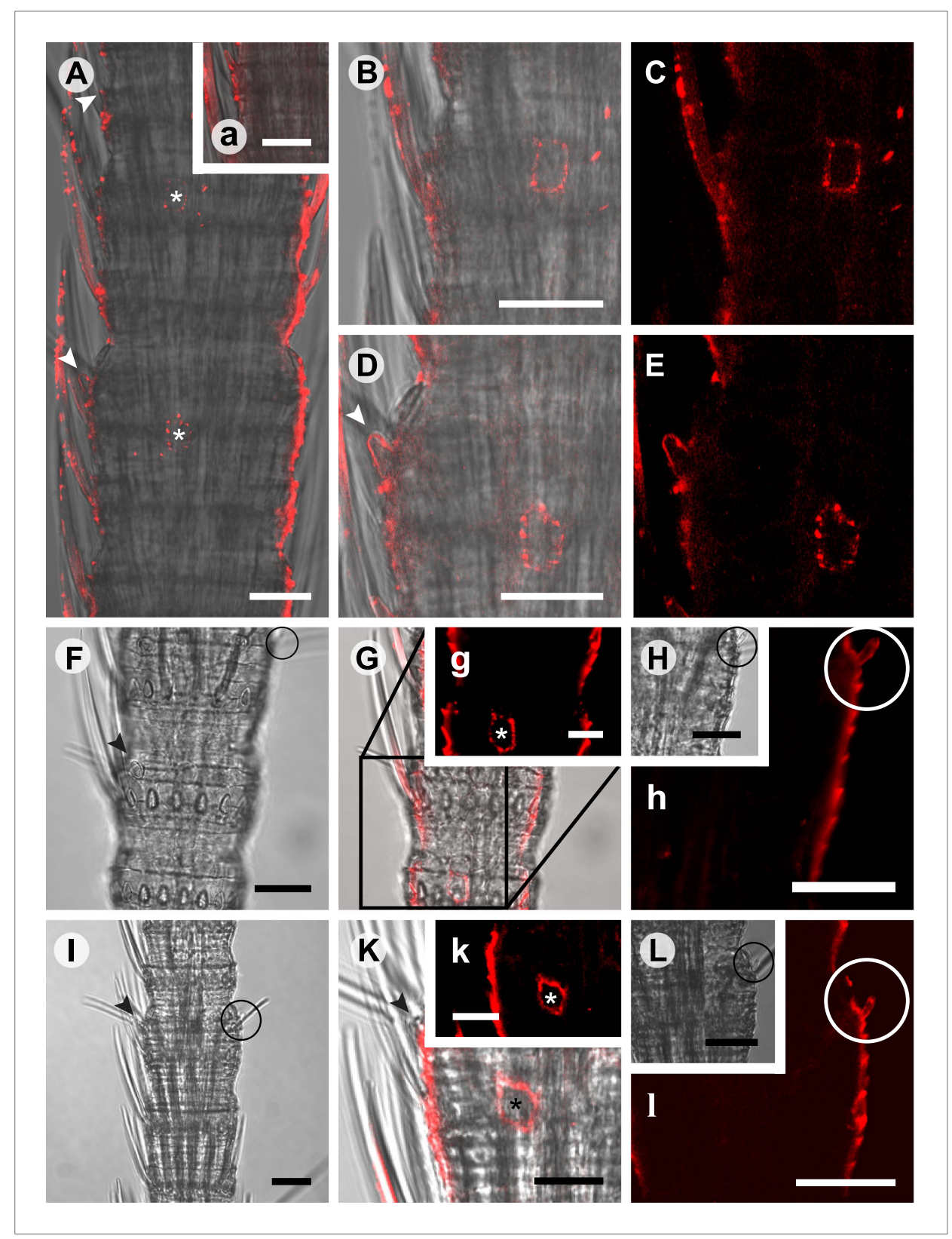

Figure 7. In situ hybridization on whole mount antennae of T. domestica using a Dig-labeled TdomOrco1 antisense probe. (A) Part of a T. domestica antenna. Combined image of fluorescent and transmitted light channel taken with CLSM. The positions of pored sensilla are indicated by arrowheads, with the upper sensillum displayed in the small box in the upper right corner. Labeled cell bodies are assigned by asterisks. (B-E) Single confocal planes through the antenna. Only a single soma close to each pored sensillum is labeled suggesting that only one neuron per sensillum expresses this Orco variant. In $\mathbf{B}$ and $\mathbf{D}$ some precipitate is visible. ( $\mathbf{C}$ and $\mathbf{E}$ ) Same image section as $\mathbf{B}$ and $\mathbf{D}$, but without transmitted light. $(\mathbf{F})$ Transmitted light image of a part of a second antenna. Location of a pored sensillum is again assigned by an arrowhead. A grooved sensillum indicated by a black circle is situated on the opposite side of the antenna. (G) Same part of the antenna taken with transmitted light and fluorescent channel. Again only one soma is labeled close to a pored sensillum. g: Only the Dig signal. Cuticle shows a strong autofluorescence on both sides. $\mathbf{H}, \mathrm{h}$ : No signal was obtained close to a grooved sensillum. (I) Part of another antenna with a pored and a grooved sensillum on the same annulus. K, k: Image section from the part of the antenna close to the pored sensillum. A single soma is labeled by the probe. k: Only the fluorescent signal. L, I: No soma was labeled close to the grooved sensillum. For sense controls view Figure 7-figure supplement 1. Scale bars A-F, H, I, L: $20 \mu \mathrm{m} ; \mathrm{g}, \mathbf{K}, \mathrm{k}: 10 \mu \mathrm{m}$. DOI: $10.7554 /$ LLife.02115.018

Figure 7. Continued on next page 
Figure 7. Continued

The following figure supplements are available for figure 7:

Figure supplement 1. In situ hybridization on the antenna of $T$. domestica using sense probes directed against the TdomOrco1.

DOI: 10.7554/eLife.02115.019

Altogether our data suggests that ORs evolved in insects after the emergence of Archaeognatha and Zygentoma, and therefore long after insects transitioned to a terrestrial lifestyle. At the time when flying insects occurred, the vegetation on earth was rapidly spreading and diversifying. ORs might not only increase the diversity of detected chemicals, but also allow the olfactory system to rapidly assess airborne odors. This is especially important for insects for which stimulus contact is very short and a fast response time is critical (Getahun et al., 2012). The oldest flying insect orders Odonta (dragonflies and damselflies) and Ephemeroptera (mayflies) were traditionally considered to be anosmic, lacking both a glomerular antennal lobe and mushroom body calyces (Strausfeld et al., 1998; Farris, 2005). Recent studies have shown that at least dragonflies have an aerial sense of smell (Rebora et al., 2012). However the small antennae and the low number of olfactory sensilla will make it even more challenging to identify putative ORs and Orco in antennal transcriptomes. ORs were definitely present in the last common ancestor of 'hemi'- and holometabolan insects at least 318-300 million years ago, with Orco present in both groups (this study, Krieger et al., 2003; Pitts et al., 2004; Smadja et al., 2009; Yang et al. 2012). The increasing dispersion of vascular plants together with the development of wings and a secondary wing articulation opened new and wider ranges of habitats and ecological niches for insects and the receptors to find them.

\section{Material and methods}

\section{Animals}

Different stages and sexes of Lepismachilis $y$-signata were collected at several locations around Jena (Germany). Animals were kept under normal light conditions and room temperature, in plastic boxes with paper towel on the ground, covered with bark with lichens, dried grassroots, and dead leaves of maple (Acer campestre, Sapindaceae). The boxes were moistened twice a week.

Firebrats of the species Thermobia domestica were obtained from a colony of the Botanical garden of Friedrich-Schiller University of Jena. Animals were maintained in a plastic container with paper towel on the bottom and egg cartons filled with cotton at around $25^{\circ} \mathrm{C}$ and $50-75 \%$ humidity, and were fed fish food (Zierfischflocke, TFH-Haimerl, Roding, Germany).

Different stages and sexes of Phyllium siccifolium were provided by the Institute of Systematic Zoology and Evolutionary Biology of the Friedrich-Schiller University of Jena. Animals were kept in a big gaze cage at $25^{\circ} \mathrm{C}$ and normal light cycle feeding on blackberry leaves. The substrate was moistened every second day.

\section{Physiology}

\section{Odorants}

Pure odorants were diluted $\left(10^{-2}\right)$ in hexane or in water as appropriate. Diluted odors $(10 \mu \mathrm{l})$ were pipetted onto a small piece of filter paper $\left(\sim 1 \mathrm{~cm}^{2}\right)$ and placed inside a glass Pasteur pipette. For odorant application, a stimulus controller was used (Stimulus Controller CS-55, Syntech, Hilversum, The Netherlands).

\section{Single sensillum recordings (SSR)}

Adult animals were immobilized and the antennae were placed in a stable position. Sensilla were localized at 1000x magnification and the extracellular analog signals originating from the OSNs were detected by inserting a tungsten wire electrode in the base of a sensillum. The reference electrode was inserted into the eye or the body. Signals were amplified (10x; Syntech Universal AC/DC Probe), sampled (10,667.0. samples/s), and filtered (100-3000 Hz with 50/60 Hz suppression) via USB-IDAC connection to a computer (Syntech). Action potentials were extracted as digital spikes from the analog signal according to top-top amplitudes using Syntech Auto Spike 32 software. Neuron activities were recorded for $10 \mathrm{~s}$, starting $2 \mathrm{~s}$ before a stimulation period of $0.5 \mathrm{~s}$. Responses of individual neurons were calculated as the increase (or decrease) in the action potential frequency (spikes/s) relative to the 


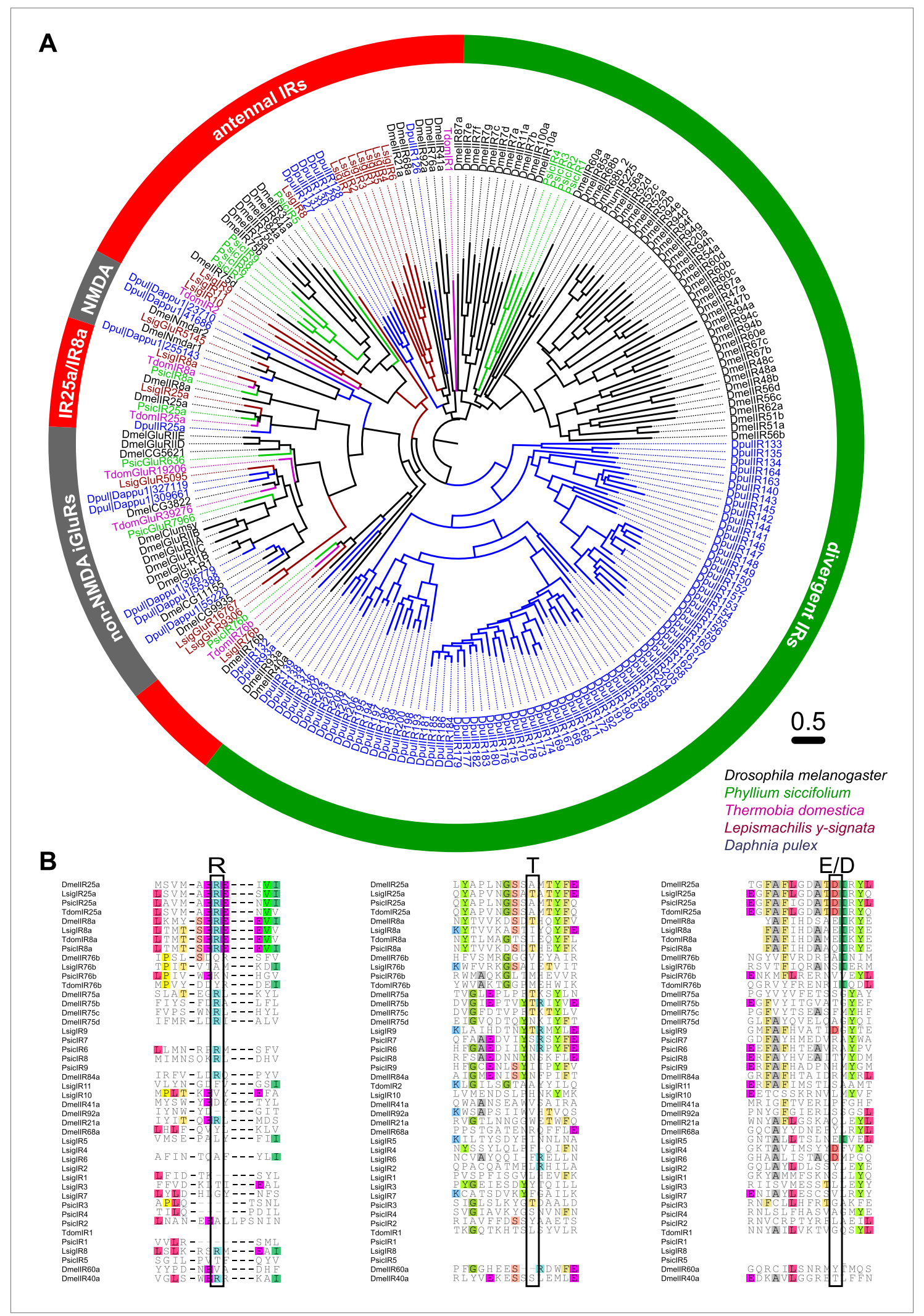

Figure 8. Ionotropic glutamate receptors of L. $y$-signata, T. domestica, and P. siccifolium. (A) Analysis of the relationship between L. $y$-signata, T. domestica, P. siccifolium, D. melanogaster and D. pulex iGluRs and IRs ( $D$. melanogaster and D. pulex sequences were sequences taken from Croset et al., 2010). Amino acid sequences were aligned using the MAFFT alignment tool plug-in in Geneious Pro 5.0.4 (BLOSUM72, gap open Figure 8. Continued on next page 
Figure 8. Continued

penalty: 1.53, offset value: 0.123, E-INS-i settings). The dendrogram was generated using maximum likelihood analysis with FastTree2. (All candidate IR sequences of L. y-signata, T. domestica, and P. siccifolium are given in Figure 8-source data 1 for amino acids and Figure 8-source data 2 for nucleotide sequences) (B) Excerpts of the alignment showing the predicted glutamate binding domains and key amino acids. Mutations in one or several of the key amino acids are a structural feature to distinguish between iGluRs and IRs, although they can be present in the coreceptors.

DOI: 10.7554/eLife.02115.020

The following source data are available for figure 8:

Source data 1. Amino acid sequences of putative variant ionotropic glutamate receptors of L. $y$-signata, T. domestica, and P. siccifolium. DOI: 10.7554/eLife.02115.021

Source data 2. Nucleotide sequences of putative variant ionotropic glutamate receptors of L. y-signata, T. domestica, and P. siccifolium. DOI: 10.7554/eLife.02115.022

Source data 3. MAFFT amino acid alignment of iGluR and IR candidates of L. y-signata, T. domestica, P. siccifolium, D. melanogaster, and D. pulex (D. melanogaster and D. pulex sequences were sequences taken from Croset et al., 2010).

DOI: 10.7554/eLife.02115.023

Source data 4. FastTree file resulting from the MSA of Figure 4-source data 3 (can be opened with FigTree). DOI: 10.7554/eLife.02115.024

Source data 5. Tree file resulting from the MSA of Figure 8-source data 3 containing node support values. DOI: 10.7554/eLife.02115.025

pre-stimulus frequency. Sensilla were classified as basiconic, coeloconic, or trichoid based on morphological criteria. Further subdivision of distinct sensillum types was based on response profiles of all the OSNs housed within, independently from their possible olfactory receptor.

\section{SEM}

Male and female antennae were cut at the base and fixed in glutaraldehyde. Antennae were dehydrated in an ascending ethanol series (70\%, 80\%,90\%, 96\%, $3 \times 100 \%$ ethanol, 10 min each), critical point dried (BAL-TEC CPD 030, Bal-Tec Union Ltd., Liechtenstein), mounted on aluminum stubs with adhesive film and sputter coated with gold on a BAL-TEC SCD005 (Bal-Tec, Balzers, Liechtenstein). Micrographs were taken with a LEO 1450 VP scanning electron microscope (Zeiss, Wetzlar, Germany).

\section{Molecular Biology and bioinformatics}

\section{RNA extraction}

Antennae and maxillary palps were cut off close to the base and were transferred to Eppendorf cups chilled over liquid nitrogen. RNA of different tissues, respectively antennae, palps, heads, whole bodies and juveniles (unscaled juvenile stadia) was isolated using TRIzol isolation following the manufacturer's instructions, but replacing chloroform with 1-bromo-3-chloro-propane. Total RNA was dissolved in RNase free water and total RNA quality and quantity measured using an Agilent Bioanalyzer (Agilent Technologies, Santa Clara, USA).

\section{Transcriptome sequencing}

RNASeq was performed for L. $y$-signata RNA using the HiSeq 2000 (TruSeq SBS v5) Sequencing System from Illumina, utilizing the single read $100 \mathrm{bp}$ (+7 index) technology at Eurofins MWG/Operon (Berlin). The resulting 22'444'128 reads were filtered for vector and linker sequences, as well as contaminants by Eurofins. A second RNASeq run for deeper sequencing was done using the HiSeq2500 at the Max Planck Genome centre in Cologne, resulting in 77'060'687 paired end reads of 100bp. Additionally to the transcriptomes of L. $y$-signata chemosensory tissues, a pooled transcriptome of whole body and head RNA was generated at Eurofins MWG/Operon (Berlin) using single read $100 \mathrm{bp}$ (+7 index) technology.

Both $T$. domestica and $P$. siccifolium RNA was sequenced using the HighSeq2500 Sequencing system generating 27'704'231 paired end reads for T. domestica and 30'762'777 paired end reads of P. siccifolium. Before sequencing rRNA depletion was performed the Max Planck Genome centre. Since the depletion did not work out for L. y-signata, a much deeper sequencing was performed in the second sequencing run as described above.

Bioinformatics

Removal of duplicate reads and de novo assembly was performed with CLC Genomics Workbench 5.5 (CLCbio, Copenhagen, Denmark). Sequence databases were generated in Geneious Pro 5.0.4 (Biomatters, Auckland, New Zealand). Within these databases, we manually tBLASTn searched for 


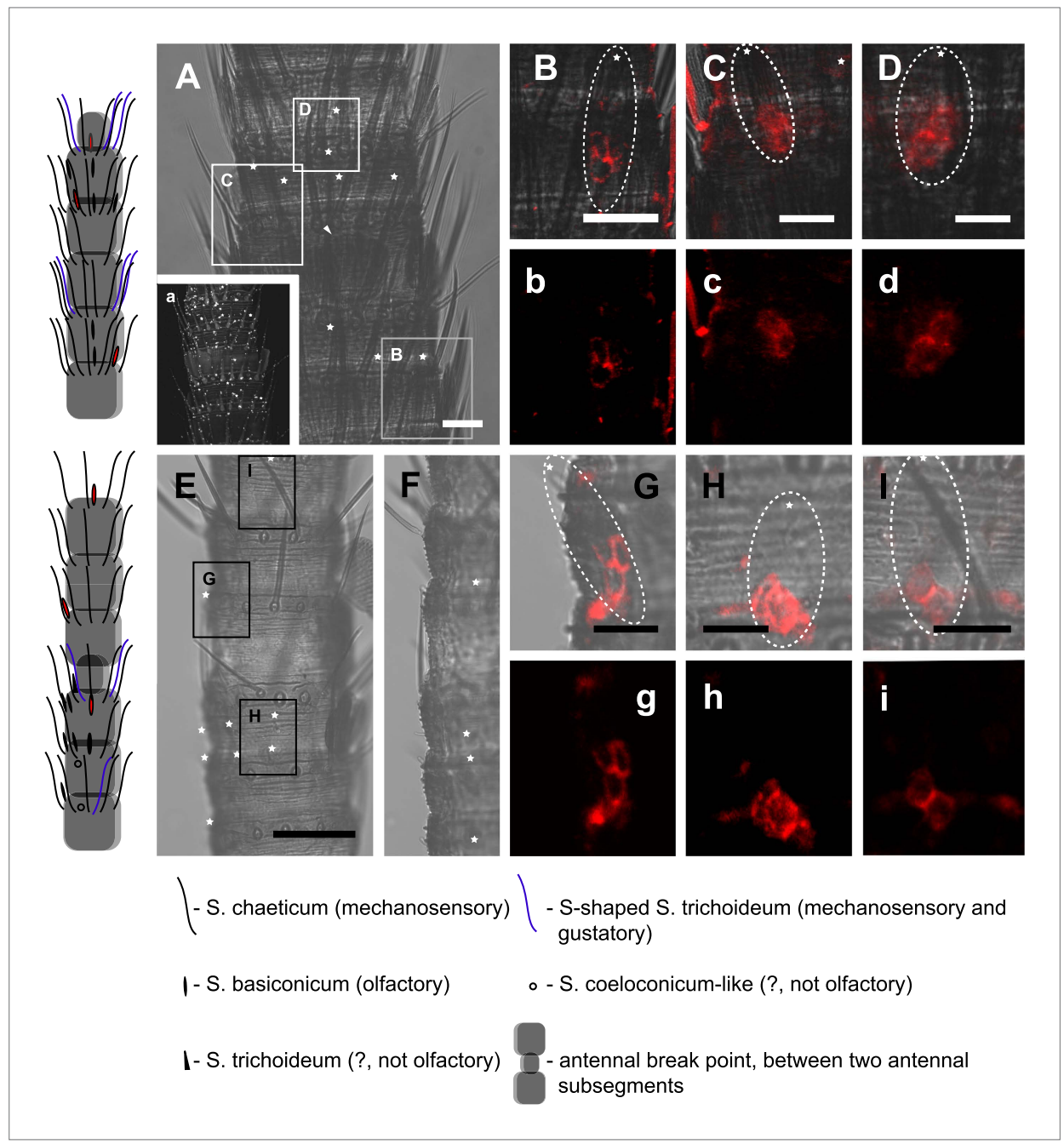

Figure 9. In situ hybridization on the antenna of L. y-signata using a Dig-labeled LsigIR25a antisense probe. On the left: schematic drawings of the position of the different sensillum types on the particular antennal subsegment. The legend for the sensillum types is given below the confocal images. (A-D) Labeling of somata in a subsegment of an antenna. Mostly two somata were labeled with the probe. The positions of the somata were in line with the positions of basiconic sensilla, but not gustatory and mechanosensory sensilla. Ultrastructural investigation of basiconic sensilla of Machilis sp. (Archaeognatha) and Lepisma saccharina (Zygentoma) suggests that the sensory neurons are located in a distance of at least $25 \mu \mathrm{m}$ from the sensillum base in the extension of the sensillum (Berg and Schmidt, 1997). Therefore, we concluded that the labeled somata correspond to neurons housed in basiconic sensilla. These sensilla were colored red in the drawing on the left. (A) Transmitted light overview with asterisks labeling basiconic sensilla. Image sections given in B-D are indicated by white boxes and the corresponding letters. a: Projection of confocal planes recorded with Argon laser at a wavelength of $488 \mathrm{~nm}$ to identify the position of basiconic sensilla. (B-D) Overlaid transmitted light and fluorescent images of labeled somata. b-d: Images without transmitted light channel. (E-I) Labeling of somata in a second antenna. Parts of two antennal segments that are separated by an antennal break point. The break point can be recognized by a thinner segment on the distal part of the antennae or by a special trichoid sensillum that is only present on the segment proximal to a breaking point. (E and F) Transmitted light images of the antenna. $\mathbf{E}$ is more from the top. Image sections given in G-I are indicated by white boxes and the corresponding letters. $\mathbf{F}$ is more central plane. Asterisks denote the location of a basiconic sensillum. (G-I) Overlaid confocal images of labeled neurons. Images are projections of three confocal planes. On some positions the cuticle is given a background signal. g-i: Images without transmitted light channel. Scale bars: A-C, G-I: $20 \mu \mathrm{m}, \mathbf{E}: 50$ m, D: $10 \mu \mathrm{m}$.

DOI: 10.7554/eLife.02115.026

Figure 9. Continued on next page 
Figure 9. Continued

The following figure supplements are available for figure 9:

Figure supplement 1. In situ hybridization on the antenna of L. y-signata using an antisense probe directed against the IR coreceptor IR8a.

DOI: 10.7554/eLife.02115.027

Figure supplement 2. In situ hybridization on the antenna of L. y-signata using sense probes directed against the IR coreceptors IR25a, IR8a.

DOI: 10.7554/eLife.02115.028

olfactory receptors (ORs), antennal ionotropic receptors (IRs), and gustatory receptors (CSPs). Templates for manual searches were the published amino acid sequences of the respective gene families of Drosophila melanogaster, Bombyx mori, Pediculus humanus, Apis mellifera, Acyrthosiphon pisum, and Daphnia pulex, as well as identified sequences of L. $y$-signata, T. domestica, and P. siccifolium.

Contigs with similarity to a member of these gene families were edited and subject to personal scrutiny of blast results, as well as further analysis. ORFs were identified and translated into amino acid sequence in Geneious Pro 5.0.4. Alignments with other members of the respective gene families were carried out using MAFFT (E-INS-I parameter set; Katoh et al., 2005). Dendrograms were calculated using maximum likelihood analysis with FastTree2 (Price et al., 2009; Liu et al., 2011) and displayed and edited with FigTree (http://tree.bio.ed.ac.uk/software/figtree). Candidates were named with the abbreviation for the gene family and ascending numbers with the exception of coreceptors, where a clear homology could be assigned. The body transcriptome of L. $y$-signata was independently screened for both ORs and Orco-related sequences.

Gene Ontology (GO) annotation was performed with Blast2GO (http://www.blast2go.com/b2ghome, Conesa et al., 2005).

HMMR-design

HMMER v3.0 (Eddy, 2011) was used to construct HMM profiles based on a multiple sequence alignment of Orco sequences of $D$. melanogaster, Apis mellifera, Tribolium castaneum, and Manduca sexta resulting in three local HMM (83bDom_1: VKHOGLVADLMPNIRLMOMVGHFMFNYYS,

83bDom_4: TVEIPRLMIKSWYPWDAMHGM,

83bDom_5: DVMFCSWLLFACEQLOHLKAIMKPLMELSASLDTYRPNS) profiles and a global HMM profile. Profiles were used to search online against $\mathrm{nr}$ (http://hmmer.janelia.org/search/phmmer) to test the quality of the generated HMM profiles. Profiles were used subsequently to screen the antennal and maxillary palp transcriptome database of $L$. $y$-signata using the command line version of HMMER.

cDNA synthesis for RT-PCR

SuperScript III First-Strand Synthesis System (Invitrogen, Life Technology, Grand Island, USA) was used for cDNA synthesis according to the manufacturer's instructions, including a DNAse digestion step.

\section{Receptor cloning}

To validate and extend candidate sequences total RNA was purified using the Poly(A)Purist MAG Kit (Ambion, Life Technologies, Grand Island, USA). Synthesis of cDNA was performed using the SMARTer RACE cDNA Amplification Kit (Clontech, Mountain View, USA). Gene-specific primers were designed against receptor candidates (Primer3 v.0.4.0, Whitehead Institute for Biomedical Research and Oligo Calc version 3.26). RACE-PCR amplification was done according to the manufacturer's instructions.

\section{FISH}

Biotin- and digoxigenin (DIG)-labeled sense and antisense probes targeting candidates were prepared using a T7/Sp6-Polymerase (ROCHE, Berlin, Germany) as per manufacturer's instructions, a Biotin RNA Labeling Mix 10x conc. (ROCHE) or DIG RNA Labeling Mix 10x conc. (ROCHE), and incubating $3 \mathrm{hr}$ at $37^{\circ} \mathrm{C}$. RNA was precipitated and washed once with $70 \%$ ethanol, dissolved in water and finally diluted in hybridization buffer. Probes were fragmented to a length of about 600 nucleotides (Angerer and Angerer, 1992).

Antennae of adult L. y-signata and T. domestica were cut off, shortly dipped in distilled water with Triton X-100 (Sigma Aldrich, St. Louis, USA) and fixed for $24 \mathrm{hr}$ in 4\% PFA (ROTH, Karlsruhe, Germany) in $1 \mathrm{M} \mathrm{NaHCO}_{3}$ (Sigma Aldrich, pH 9.5). The antennae were washed in 1xPBS containing 
0,03\% TritonX100 and incubated in $0.2 \mathrm{M} \mathrm{HCl}(0.03 \%$ TritonX100) for $10 \mathrm{~min}$. Afterwards, antennae were rinsed twice in $1 \times \mathrm{PBS}(1 \%$ TritonX100) and autoclaved distilled water. After incubation in $2 \times S S C\left(3 \mathrm{M} \mathrm{NaCl}, \mathrm{ROTH} ; 0.3 \mathrm{M} \mathrm{C}_{6} \mathrm{H}_{5} \mathrm{Na}_{3} \mathrm{O}_{7} \star 2 \mathrm{H}_{2} \mathrm{O}\right.$, Sigma; $\left.\mathrm{pH} 7.1\right)$ at $70^{\circ} \mathrm{C}$ a treatment with Proteinase $\mathrm{K}$ $\left(1 \mathrm{U} / \mathrm{ml}\right.$ Proteinase Buffer) at $37^{\circ} \mathrm{C}$ for $30 \mathrm{~min}$ followed. The antennae were thoroughly washed in PBS and fixed again for $20 \mathrm{~min}$. Fixative was washed away with PBS and antennae pre-hybridized in Hybridization Buffer for $8 \mathrm{hr}$ at $55^{\circ} \mathrm{C}$. Hybridization was performed at $55^{\circ} \mathrm{C}$ for 2 to 3 days. DIG-labeled probes were detected using an anti-DIG-conjugated antibody in combination with HNPP/FastRed (HNPP Fluorescent Detection Set, Roche), biotin-labeled probe using a TSATM Flouresin System. Preparations were analyzed using a Zeiss LSM510 Meta (Zeiss, Jena, Germany).

Due to the modular organization of the antenna, with compartments of a size varying between 5 and 12 annuli, and to the repetitive pattern of olfactory sensilla between the compartments, we did not need to map labeling of neurons along the whole antenna.

\section{Image processing}

Contrast and false color images were optimized in Zeiss LSM Image Browser (Version 4,0,0,157). Further image processing, including cutting and image mode conversion was done in Adobe Photoshop CS4, figures were prepared in Adobe Illustrator CS4.

\section{Acknowledgements}

We thank Christin Grossmann and Sascha Bucks for technical assistance in sample preparation and receptor cloning. The authors thank Renate Kaiser and Sandor Nietzsche (both Electron Microscopy Center Jena) for help with the scanning electron microscope, Richard Reinhardt and Liza Czaja (both Max Planck Genome Center) for support in transcriptome sequencing. We also thank Shannon Olsson and Dieter Wicher for critical comments on the manuscript.

\section{Additional information}

Funding

\begin{tabular}{ll} 
Funder & Author \\
\hline Max Planck Society & Bill S Hansson
\end{tabular}

The funder had no role in study design, data collection and interpretation, or the decision to submit the work for publication.

Author contributions

$\mathrm{CM}$, Conception and design, Acquisition of data, Analysis and interpretation of data, Drafting or revising the article; HKMD, Conception and design, Acquisition of data, Analysis and interpretation of data; HV, MCS, Analysis and interpretation of data, Drafting or revising the article; AV, Drafting or revising the article, Contributed unpublished essential data or reagents; BSH, Conception and design, Drafting or revising the article; EG-W, Conception and design, Analysis and interpretation of data, Drafting or revising the article

\section{Additional files}

Major dataset

The following dataset was generated:

\begin{tabular}{l} 
Author(s) \\
\hline Missbach C, \\
Dweck HKM, \\
Vogel H, Vilcinskas A, \\
Stensmyr MC, \\
Hansson BS, and \\
Grosse-Wilde E
\end{tabular}

Year Dataset title Dataset ID and/or URL

2014 Evolution of insect olfactory receptors - RNAseq

PRJEB5093; http://www. ebi.ac.uk/ena/data/view/ PRJEB5093
Database, license, and accessibility information

Publicly available at the European Nucleotide Archive (http://www.ebi. ac.uk/ena/). 


\section{References}

Adel T. 1984. Sensilla and sensilla pattern on the antenna of Thermobia domestica and Lepisma saccharina (Insecta: Zygentoma). Braunschweiger Naturkundliche Schriften 2:191-218.

Ai M, Min S, Grosjean Y, Leblanc C, Bell R, Benton R, Suh GS. 2010. Acid sensing by the Drosophila olfactory system. Nature 468:691-695. doi: 10.1038/nature09537.

Abuin L, Bargeton B, Ulbrich MH, Isacoff EY, Kellenberger S, Benton R. 2011. Functional architecture of olfactory ionotropic glutamate receptors. Neuron 69:44-60. doi: 10.1016/j.neuron.2010.11.042.

Altner H, Prillinger L. 1980. Ultrastructure of invertebrate chemo-, thermo- and hygroreceptors and its functional significance. International Review of Cytology 67:69-139. doi: 10.1016/S0074-7696.

Angerer LM, Angerer RC. 1992. In situ hybridization to cellular RNA with radiolabeled RNA probes. In: Wilkinson DG, editor. In Situ Hybridization. A practical approach. Oxford: IRL Press. p. 15-32.

Benton R, Vannice KS, Gomez-Diaz C, Vosshall LB. 2009. Variant ionotropic glutamate receptors as chemosensory receptors in Drosophila. Cell 136:149-162. doi: 10.1016/j.cell.2008.12.001.

Benton R, Sachse S, Michnick SW, Vosshall LB. 2006. A typical membrane topology and heteromeric function of Drosophila odorant receptors in vivo. PLOS Biology 4:e20. doi: 10.1371/journal.pbio.0040020.

Berg J, Schmidt K. 1997. Comparative morphology and moulting of Sensilla basiconica of Lepisma saccharina Linnaeus (Zygentoma: Lepismatidae) and Machilis sp. (Archaeognatha: Machilidae). International Journal of Insect Morphology \& Embryology 26:161-172. doi: 10.1016/S0020-7322(97)00018-4.

Bockhorst KG. 1988. Patterns of sensilla on the antennae of some Machilidae (Insecta, Archaeognatha). Braunschweiger Naturkundliche Schriften 3:137-170.

Boore JL, Lavrov DV, Brown WM. 1998. Gene translocation links insects and crustaceans. Nature 392:667-668. doi: $10.1038 / 33577$.

Buck L, Axel R. 1991. A novel multigene family may encode odorant receptors: a molecular basis for odor recognition. Cell 65:175-187. doi: 10.1016/0092-8674(91)90418-X.

Clyne PJ, Warr CG, Freeman MR, Lessing D, Kim J, Carlson JR. 1999. A novel family of divergent seventransmembrane proteins: candidate odorant receptors in Drosophila. Neuron 22:327-338. doi: 10.1016/ S0896-6273(00)81093-4.

Clyne PJ, Warr CG, Carlson JR. 2000. Candidate taste receptors in Drosophila. Science 287:1830-1834. doi: 10.1126/science.287.5459.1830.

Conesa A, Götz S, García-Gómez JM, Terol J, Talón M, Robles M. 2005. Blast2GO: a universal tool for annotation, visualization and analysis in functional genomics research. Bioinformatics 21:3674-3676. doi: 10.1093/ bioinformatics/btib10.

Croset V, Rytz R, Cummins SF, Budd A, Brawand D, Kaessmann H, Gibson TJ, Benton R. 2010. Ancient protostome origin of chemosensory ionotropic glutamate receptors and the evolution of insect taste and olfaction. PLOS Genetics 6:e1001064. doi: 10.1371/journal.pgen.1001064.

Eddy SR. 2011. Accelerated profile HMM searches. PLOS Computational Biology 7:e1002195. doi: 10.1371/ journal.pcbi.1002195.

Elmore T, Ignell R, Carlson JR, Smith DP. 2003. Targeted mutation of a Drosophila odor receptor defines receptor requirement in a novel class of sensillum. Journal of Neuroscience 23:9906-9912.

Farris SM. 2005. Evolution of insect mushroom bodies: old clues, new insights. Arthropod Structure \& Development 34:211-234. doi: 10.1016/j.asd.2005.01.008.

Firestein S. 2001. How the olfactory system makes sense of scents. Nature 413:211-218. doi: 10.1038/35093026.

Friedrich M, Tautz D. 1995. Ribosomal DNA phylogeny of the major extant arthropod classes and the evolution of myriapods. Nature 376:165-167. doi: 10.1038/376165a0.

Fröhlich A, Lu Z. 2013. The "rosette-like" structures in the cuticle of Petrobius brevistylis are the openings of epidermal glands. Arthropod Structure \& Development 42:89-94. doi: 10.1016/j.asd.2012.10.001.

Gao Q, Chess A. 1999. Identification of candidate Drosophila olfactory receptors from genomic DNA sequence. Genomics 60:31-39. doi: 10.1006/geno.1999.5894.

Getahun MN, Wicher D, Hansson BS, Olsson SB. 2012. Temporal response dynamics of Drosophila olfactory sensory neurons depends on receptor type and response polarity. Frontiers in Cellular Neuroscience 6:1-11. doi: 10.3389/fncel.2012.00054.

Guo M, Krieger J, Grosse-Wilde E, Mißbach C, Zhang L, Breer H. 2014. Variant ionotropic receptors are expressed in olfactory sensory neurons of coeloconic sensilla on the antenna of the desert locust (Schistocerca gregaria). International Journal of Biological Sciences 10:1-14. doi: 10.7150/ijbs.7624.

Hallem EA, Ho MG, Carlson JR. 2004. The molecular basis of odor coding in the Drosophila antenna. Cell 117:965-979. doi: 10.1016/j.cell.2004.05.012.

Hansen-Delkeskamp E. 2001. Responsiveness of antennal taste hairs of the apterygotan insect, Thermobia domestica (Zygentoma); an electrophysiological investigation. Journal of Insect Physiology 47:689-697. doi: 10.1016/S0022-1910(00)00159-1.

Hildebrand JG, Shepherd GM. 1997. Mechanisms of olfactory discrimination: converging evidence for common principles across phyla. Annual Review of Neuroscience 20:595-631. doi: 10.1146/annurev.neuro.20.1.595.

Hill CA, Fox AN, Pitts RJ, Kent LB, Tan PL, Chrystal MA, Cravchik A, Collins FH, Robertson HM, Zwiebel LJ. 2002. G protein coupled receptors in Anopheles gambiae. Science 298:176-178. doi: 10.1126/ science.1076196.

Hollins B, Hardin D, Gimelbrant AA, McClintock TS. 2003. Olfactory-enriched transcripts are cell-specific markers in the lobster olfactory organ. The Journal of Comparative Neurology 455:125-138. doi: 10.1002/cne.10489. 
Katoh K, Kuma K, Toh H, Miyata T. 2005. MAFFT version 5: improvement in accuracy of multiple sequence alignment. Nucleic Acids Research 33:511-518. doi: 10.1093/nar/gki198.

Kirkness EF, Haas BJ, Sun W, Braig HR, Perotti MA, Clark JM, Lee SH, Robertson HM, Kennedy RC, Elhaik E, Gerlach D, Kriventseva EV, Elsik CG, Graur D, Hill CA, Veenstra JA, Walenz B, Tubío JM, Ribeiro JM, Rozas J, Johnston JS, Reese JT, Popadic A, Tojo M, Raoult D, Reed DL, Tomoyasu Y, Kraus E, Mittapalli O, Margam VM, Li HM, Meyer JM, Johnson RM, Romero-Severson J, Vanzee JP, Alvarez-Ponce D, Vieira FG, Aguadé M, Guirao-Rico S, Anzola JM, Yoon KS, Strycharz JP, Unger MF, Christley S, Lobo NF, Seufferheld MJ, Wang N, Dasch GA, Struchiner CJ, Madey G, Hannick LI, Bidwell S, Joardar V, Caler E, Shao R, Barker SC, Cameron S, Bruggner RV, Regier A, Johnson J, Viswanathan L, Utterback TR, Sutton GG, Lawson D, Waterhouse RM, Venter JC, Strausberg RL, Berenbaum MR, Collins FH, Zdobnov EM, Pittendrigh BR. 2010. Genome sequences of the human body louse and its primary endosymbiont provide insights into the permanent parasitic lifestyle. Proceedings of the National Academy of Sciences of the United States of America 107:12168-12173. doi: 10.1073/pnas.1003379107.

Krång A-S, Knaden M, Steck K, Hansson BS. 2012. Transition from sea to land: olfactory function and constraints in the terrestrial hermit crab Coenobita clypeatus. Proceedings Biological Sciences/The Royal Society 279: 3510-3519. doi: 10.1098/rspb.2012.0596.

Krieger J, Klink O, Mohl C, Raming K, Breer H. 2003. A candidate olfactory receptor subtype highly conserved across different insect orders. Journal of Comparative Physiology A, Neuroethology, Sensory, Neural, and Behavioral Physiology 189:519-526. doi: 10.1007/s00359-003-0427-x.

Kumar BN, Taylor RW, Pask GM, Zwiebel LJ, Newcomb RD, Christie DL. 2013. A conserved aspartic acid is important for agonist (VUAA1) and odorant/tuning receptor-dependent activation of the insect odorant co-receptor (Orco). PLOS ONE 8:e70218. doi: 10.1371/journal.pone.0070218.

Larsson MC, Domingos Al, Jones WD, Chiappe ME, Amrein H, Vosshall LB. 2004. Or83b encodes a broadly expressed odorant receptor essential for Drosophila olfaction. Neuron 43:703-714. doi: 10.1016/j. neuron.2004.08.019.

Liu K, Linder CR, Warnow T. 2011. RAxML and FastTree: comparing two methods for large-scale maximum likelihood phylogeny estimation. PLOS ONE 6:e27731. doi: 10.1371/journal.pone.0027731.

Lundin C, Käll L, Kreher SA, Kapp K, Sonnhammer EL, Carlson JR, Heijne Gv, Nilsson I. 2007. Membrane topology of the Drosophila OR83b odorant receptor. FEBS Letters 581:5601-5604. doi: 10.1016/j.febslet.2007.11.007.

Missbach C, Harzsch S, Hansson BS. 2011. New insights into an ancient insect nose: the olfactory pathway of Lepismachilis y-signata (Archaeognatha: Machilidae). Arthropod Structure \& Development 40:317-333. doi: 10.1016/j.asd.2011.03.004.

Mombaerts P. 1999. Seven-transmembrane proteins as odorant and chemosensory receptors. Science $\mathbf{2 8 6}$ 707-711. doi: 10.1126/science.286.5440.707.

Nakagawa T, Pellegrino M, Sato K, Vosshall LB, Touhara K. 2012. Amino acid residues contributing to function of the heteromeric insect olfactory receptor complex. PLOS ONE 7:e32372. doi: 10.1371/journal.pone.0032372.

Peñalva-Arana DC, Lynch M, Robertson HM. 2009. The chemoreceptor genes of the waterflea Daphnia pulex: many Grs but no Ors. Bmc Evolutionary Biology 9:79. doi: 10.1186/1471-2148-9-79.

Pitts RJ, Fox AN, Zwiebel LJ. 2004. A highly conserved candidate chemoreceptor expressed in both olfactory and gustatory tissues in the malaria vector Anopheles gambiae. Proceedings of the National Academy of Sciences of the United States of America 101:5058-5063. doi: 10.1073/pnas.0308146101.

Price MN, Dehal PS, Arkin AP. 2009. FastTree: computing large minimum evolution trees with profiles instead of a distance matrix. Molecular Biology and Evolution 26:1641-1650. doi: 10.1093/molbev/msp077.

Rebora M, Salerno G, Piersanti S, Dell'Otto A, Gaino E. 2012. Olfaction in dragonflies: electrophysiological evidence. Journal of Insect Physiology 58:270-277. doi: 10.1016/j.jinsphys.2011.11.018.

Regier JC, Shultz JW, Zwick A, Hussey A, Ball B, Wetzer R, Martin JW, Cunningham CW. 2010. Arthropod relationships revealed by phylogenomic analysis of nuclear protein-coding sequences. Nature 463:1079-1083. doi: 10.1038/nature08742.

Robertson HM. 2001. Taste: independent origins of chemoreception coding systems? Current Biology 11: 560-562. doi: 10.1016/S0960-9822(01)00343-8.

Robertson HM, Warr CG, Carlson JR. 2003. Molecular evolution of the insect chemoreceptor gene superfamily in Drosophila melanogaster. Proceedings of the National Academy of Sciences of the United States of America 100:14537-14542. doi: 10.1073/pnas.2335847100.

Robertson HM, Thomas JH. 2006. The putative chemoreceptor families of C. elegans (January 06, 2006). In: The C. elegans Research Community, editor. WormBook. doi: 10.1895/wormbook.1.66.1. http://www.wormbook.org

Robertson HM, Wanner KW. 2006. The chemoreceptor superfamily in the honey bee Apis mellifera: expansions of the odorant, but not gustatory, receptor families. Genome Research 16:1395-1403. doi: 10.1101/gr.5057506.

Rota-Stabelli O, Daley AC, Pisani D. 2013. Molecular timetrees reveal a Cambrian colonization of land and a new scenario for ecdysozoan evolution. Current Biology 23:392-398. doi: 10.1016/j.cub.2013.01.026.

Sargsyan V, Getahun MN, Lavista Llanos S, Olsson SB, Hansson BS, Wicher D. 2011. Phosphorylation via PKC regulates the function of the Drosophila odorant co-receptor. Frontiers in Cellular Neuroscience 5:5. doi: 10.3389/fncel.2011.00005.

Sato K, Pellegrino M, Nakagawa T, Nakagawa T, Vosshall LB, Touhara K. 2008. Insect olfactory receptors are heteromeric ligand-gated ion channels. Nature 452:1002-1006. doi: 10.1038/nature06850.

Scott K, Brady R Jnr, Cravchik A, Morozov P, Rzhetsky A, Zuker C, Axel R. 2001. A chemosensory gene family encoding candidate gustatory and olfactory receptors in Drosophila. Cell 104:661-673. doi: 10.1016/ S0092-8674(01)00263-X. 
Silbering AF, Rytz R, Grosjean Y, Abuin L, Ramdya P, Jefferis GS, Benton R. 2011. Complementary function and integrated wiring of the evolutionarily distinct Drosophila olfactory subsystems. Journal of Neuroscience 31:13357-13375. doi: 10.1523/jneurosci.2360-11.2011.

Smadja C, Shi P, Butlin RK, Robertson HM. 2009. Large gene family expansions and adaptive evolution for odorant and gustatory receptors in the pea aphid, Acyrthosiphon pisum. Molecular Biology and Evolution 26:2073-2086. doi: 10.1093/molbev/msp116.

Strausfeld NJ, Hansen L, LI Y, Gomez RS, Ito K. 1998. Evolution, discovery, and interpretations of arthropod mushroom bodies. Learning \& Memory 5:11-37. doi: 10.1101//m.5.1.11.

Tadesse T, Schmidt M, Walthall WW, Tai PC, Derby CD. 2011. Distribution and function of splash, an achaetescute homolog in the adult olfactory organ of the Caribbean spiny lobster Panulirus argus. Developmental Neurobiology 71:316-335. doi: 10.1002/dneu.20862.

Tauxe GM, MacWilliam D, Boyle SM, Guda T, Ray A. 2013. Targeting a dual detector of skin and CO2 to modify mosquito host seeking. Cell 155:1365-1379. doi: 10.1016/j.cell.2013.11.013.

Trautwein MD, Wiegmann BM, Beutel R, Kjer KM, Yeates D. 2012. Advances in insect phylogeny at the dawn of the postgenomic era. Annual Review of Entomology 57:499-468. doi: 10.1146/annurev-ento-120710-100538.

Vosshall LB, Amrein H, Morozov PS, Rzhetsky A, Axel R. 1999. A spatial map of olfactory receptor expression in the Drosophila antenna. Cell 96:725-736. doi: 10.1016/s0092-8674(00)80582-6.

Vosshall LB, Hansson BS. 2011. A unified nomenclature system for the insect olfactory coreceptor. Chemical Senses 36:497-498. doi: 10.1093/chemse/bjr022.

Wicher D, Schäfer R, Bauernfeind R, Stensmyr MC, Heller R, Heinemann SH, Hansson BS. 2008. Drosophila odorant receptors are both ligand-gated and cyclic-nucleotide-activated cation channels. Nature $\mathbf{4 5 2}$ 1007-1011. doi: 10.1038/nature06861.

Wiegmann BM, Trautwein MD, Kim JW, Cassel BK, Bertone MA, Winterton SL, Yeates DK. 2009. Single-copy nuclear genes resolve the phylogeny of holometabolous insects. BMC Biology 7:1-16. doi: 10.1186/1741-7007-7-34.

Yang Y, Krieger J, Zhang L, Breer H. 2012. The olfactory co-receptor Orco from the migratory locust (Locusta migratoria) and the desert locust (Schistocerca gregaria): identification and expression pattern. International Journal of Biological Sciences 8:159-170. doi: 10.7150/ijbs.8.159.

Zhou X, Slone JD, Rokas A, Berger SL, Liebig J, Ray A, Reinberg D, Zwiebel LJ. 2012. Phylogenetic and transcriptomic analysis of chemosensory receptors in a pair of divergent ant species reveals sex-specific signatures of odor coding. PLOS Genetics 8:e1002930. doi: 10.1371/journal.pgen.1002930. 